\title{
Title: Direct Molecular Evolution of Detergent-Stable G Protein-Coupled Receptors using Polymer Encapsulated Cells
}

\section{Authors: Daniel J. Scott ${ }^{1,2}$ and Andreas Plückthun ${ }^{1 *}$}

\section{Affiliations:}

${ }^{1}$ Department of Biochemistry, The University of Zurich, Winterthurerstrasse 190, 8057 Zurich, Switzerland.

${ }^{2}$ Present address: Florey Neuroscience Institutes and Department of Biochemistry and Molecular Biology, The University of Melbourne, Parkville, Victoria 3010, Australia. *Correspondence to:

Prof. Andreas Plückthun

Biochemisches Institut, Universität Zürich

Winterthurerstr. 190, CH-8057 Zürich

Switzerland

Tel $\quad+41(0) 446355570$

Fax $\quad+41(0) 446355712$

Email plueckthun@bioc.uzh.ch 


\section{Abstract:}

G protein-coupled receptors (GPCRs) are the largest class of pharmaceutical protein targets, yet drug development is encumbered by a lack of information about their molecular structure and conformational dynamics. Most mechanistic and structural studies as well as in vitrodrug screeningwith purifiedreceptorsrequire detergent solubilization of the GPCR, but typically these proteins exhibit only low stability in detergent micelles. We have developed the first directed evolution method that allows the directselection of GPCRsstable in a chosen detergent from libraries containing over one hundred million individual variants. The crucial concept was to encapsulate singleEscherichia coli cells of a library, each expressing a different GPCR variant, to form detergent-resistant, semi-permeable nano-containers. Unlike naked cells, these containers arenot dissolved by detergents, allowing us tosolubilize the GPCR proteins in situ while maintaining an association with the protein's genetic information, a prerequisite for directed evolution. The pore size was controlled to permit GPCR ligands to permeate, but the solubilized receptor to remain within the nanocapsules.Fluorescently labeled ligands were used to bind tothose GPCR variants inside the nano-containers that remained active in the detergent tested.By using fluorescence-activated cell sorting, detergent stable mutants derived from two different family A GPCRs could be identified, some with the highest stability reportedin short-chain detergents. In principle, this

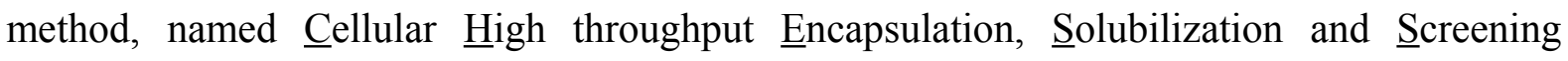
(CHESS), is not limited to engineering stabilized GPCRs, but could be used to stabilize other proteins for biochemical and structural studies.

Keywords: G Protein-Coupled Receptor, directed evolution, stabilization, encapsulation, detergent 
Abbreviations: GPCR, G protein-coupled receptor; IMP, integral membrane protein; CHESS, cellular high throughput encapsulation solubilization and screening; NT, neurotensin peptide; FACS, fluorescence-activated cell sorting; EDTA, ethylenediaminetetraacetic acid; DDM, $n$-dodecyl- $\beta$-D-maltopyranoside; DM, $n$-decyl- $\beta$-D-maltopyranoside; OG, $n$-octyl- $\beta$ D-glucopyranoside; CHAPS, 3-[(3-cholamidopropyl)dimethylammonio]-1-propanesulfonate; CHS, cholesteryl hemisuccinate; HTS, high throughput screening. 


\section{Introduction}

Over $30 \%$ of human genes encode membrane proteins and an astounding 39 of the top 50 prescription drugs sold in the U.S.A. in 2010 (78\%) mediate their pharmaceutical actions by targeting various integral membrane proteins (IMPs) (http://www.drugs.com/top200.html). Despite the major clinical relevance of IMPs, less than $1 \%$ of Protein Data Bank (PDB) entries are IMP structures ${ }^{1}$. This discrepancy is primarily due to the unstable nature of IMPs when they are removed from the lipid bilayers of the cell using detergents, an essential step for the purification of IMPs for biochemical and structural studies. The behavior of IMPs in detergent can be improved by inserting stabilizing amino acid mutations into the protein $\frac{4-21}{\text { to }}$ enable the biochemical, biophysical and sometimes even structural characterization of the stabilized IMPs. The identification of stabilizing mutations, however, is not trivial, with most of the examples above using a laborious process involving mutagenesis and screening of many individual mutants, one by one, for increased stability. Using this workflow, only small numbers of mutants can be screened, limiting the sequence space that can be sampled. Because IMPs are typically large proteins containing over 300 amino acids, to maximize the chances of identifying stabilizing mutations and identify any additive or synergistic effects from combinations of mutations, methods are needed where hundreds of millions of mutants can be screened rapidly.

Proteins with improved properties can be generated using directed evolution, which involves the enrichment of beneficial protein mutations from large mutant libraries through several generations of randomization and selection. In contradistinction to screening, where a small number of mutated clones are tested one by one, and where the clones are kept in separate cultures, in a libraryto be subjected to selectionall clones are mixed. This permits a much larger number of mutants to be evaluated, provided a selection technologyis available 
to isolate mutants from this extremely diverse mixturefor the desired property of detergent stability. The present study provides for the first time such a technology to selectdetergentstable variants of membrane proteins from a very diverse library of $10^{8}$ mutants.Such libraries can be generated using error-prone polymerases, which randomly substitute bases inDNA fragments during polymerization, or they can be completely synthetic. The challenge to be solved in the present study was that directed evolutionrequires that a physical association can be establishedbetween the mutant DNA fragment and the encoded protein:the isolation of a desired protein variant must allow the purification of the encoding DNA, which can be carried forward into further generations of selection.

Directed evolution has recently been applied to several G protein-coupled receptors (GPCRs), the largest IMP gene family in humans, to generate GPCR mutants expressing high amounts of functional protein. In these studies, approximately one hundred million $\left(10^{8}\right)$ individual mutants were expressed in $E$. coli, where the cell served to maintain the association between the mutant protein and the plasmid encoding it, through several cycles of selection for high functional expression, i.e., of correctly folded protein in the membrane. High expressing mutants were generally found to be more stable in mild detergents, yet resistance to short-chain detergents was shown only by a subset of these mutants. Such rare mutants were only identified when after selection, another screening step of single mutants was introduced.From the obtained population of high-expressing variants, individual mutants were subsequently screened for stability in short-chain detergents, one by one, rather than as a population ${ }^{21}$. Thus, it would be of great interest to select the IMP library population for stability in the detergent of choice directly. This waythe whole library will be tested for stability in the relevant detergent andnot just a small subset of the population. The most promising pool of detergent-stable IMPs can then be subjected to another round of mutagenesis and selection. 
The directed evolution of detergent stable IMPs poses a great technical challenge because the addition of detergent would lead to the dissolution of the cells, severing the association between a given protein mutant and the corresponding DNA.To circumvent this problem we sought to generate detergent-resistant containers, derived from single cells, which would physically enclose detergent-solubilized IMP mutants and the plasmids encoding them, allowing the direct selection of detergent-stable IMPs from diverse libraries containing up to one hundred million mutants. To implement this concept, our idea was to encapsulate the bacterial cell in a detergent-resistant matrix, which would need to be impermeable for large molecules such as solubilized GPCRs, but permeable for small molecules, such as their ligands, to permit subsequent selections for functionality. Thisnovel concept was termed Cellular High throughput Encapsulation, Solubilization and Screening (CHESS) (Fig. 1).

\section{Results}

\section{Cell to container conversion through encapsulation}

Only few methods have been described for the efficient encapsulation of discrete single cells, as most methods lead to the encapsulation of cell populations or aggregates. Single cell encapsulation isa crucial requirement for the selection of single mutants from diverse libraries because each mutant in the population needs to be assessed individually. Layer-by-layer selfassembly of polyelectrolytes has been used to encapsulate single yeast $\underline{26}$ and bacterial cells $\underline{27}$, and we chose to adapt and optimize this technology for our particular needs. The method takes advantage of the negative surface charge of the $E$. coli cells, which aids in the deposition of a positively charged polymer, chitosan (poly-D-glucosamine) and a subsequent layer of a negatively charged polymer, alginate (Fig. 2a-c). Analysis of cells encapsulated 
with one layer of chitosan and one layer of alginate using transmission electron microscopy revealed that the cells retained their shape and integrity, even after exposure to detergent solutions for over $24 \mathrm{~h}$ (Fig. 2d-f), and indicated that the resulting containers may behave in a way that would facilitate the evolution of IMPs. However, we found that the published method describingLbL encapsulation of $E$. coli $\stackrel{27}{~ r e s u l t e d ~ i n ~ e x c e s s i v e ~ c e l l ~ a g g r e g a t i o n, ~}$ which would severely limit the utility of the method for single clone selection (Fig. 3a). Furthermore, only half of the non-aggregated cells were completely encapsulated, as judged by the loss of $50 \%$ of the single cell-like particles in the encapsulated sample upon detergent treatment (Fig. 3b).

We hypothesized that divalent cations in solution, and bound to the cell surface, may be interfering with the deposition of the initial chitosan layer, leading to inefficient coating and cell aggregation. The addition of $1 \mathrm{mM}$ ethylenediamine tetraacetic acid (EDTA) to the buffer during polymeric coating resulted in asignificant reduction in cell aggregation (Fig. 3a), but did not significantly increase the percentage of detergent-resistant capsules in the final encapsulated sample (data not shown). Reducing the $\mathrm{pH}$ of chitosan solutions has been shown to reduce polymer aggregation by increasing electrostatic repulsion along the polymer chain, leading to more homogeneous adsorption onto a non-biological surface ${ }^{28}$. Interestingly, when we lowered the $\mathrm{pH}$ of the polymer coating solutions, the cellular encapsulation efficiency, as judged by the detergent resistance of the samples after encapsulation, was significantly improved, probably by improving the adsorption of chitosan onto the $E$. coli surface (Fig. 3b).

\section{Capsule characterization}

Flow cytometry with absolute cell counting was used to characterize preparations of encapsulated E. coli. The optimized encapsulation conditions produced preparations 
consisting of mostly single-cell sizedcapsules (Fig. $4 \mathrm{a}$ and $4 \mathrm{~b}$ ). We assessed the stability of the capsules in detergent solution compared to naked cells by determining the concentration of single-cell sized particles in detergent-treated samples over a 15 day period (Fig. 4c). Critically, samples of encapsulated cells were mostly detergent-resistant, with a mere $20 \%$ reduction in cell sized particles after 15 days with vigorous shaking in detergent. Naked cell populations, on the other hand, were rapidly solubilized by the detergent, with a $70 \%$ reduction in cell sized particles after only 24 hours.

For our purposes, it was important that detergent treatment would lead to the solubilization, but retention of GPCR proteins within the capsules. To test for the retention of receptors within the capsules, cells expressing superfolder Green Fluorescent Protein (sfGFP) tagged GPCRs were encapsulated and treated with two detergent solutions over 15 days. By measuring the sfGFP fluorescence of the capsules over time, it was evident that solubilized receptors were retained within the nanocapsules, with no significant reduction in signal, even after 15 days (Fig. 4d).

Next we ensured that functional, detergent-solubilized GPCR molecules could be detected within the capsules and that stable GPCRs could be differentiated from unstable GPCR variants. For these experiments, two previously characterized mutants of the rat neurotensin receptor $\left(\mathrm{rNTS}_{1}\right)$ were used. $\mathrm{NTS}_{1}$-D03 is a high expressing variant of $\mathrm{rNTS}_{1}$ that is stable in a mild detergent mix (DCC $)^{\frac{14}{4}}$. FACS sorting of permeabilized cells expressing receptor libraries was previously used to identify a more stable version of $\mathrm{NTS}_{1}-\mathrm{D} 03, \mathrm{NTS}_{1}$ C7E02, which is stable in the harsher detergent,decyl- $\beta$-D-maltopyranoside(DM $)^{21}$. We tested ligand binding to these receptors withflow cytometry, using fluorescently labeled NTS 1 ligand, HiLyte Fluor 647-labeled neurotensin (HL-NT). Critically, HL-NTwas able to diffuse in through the capsule pores and bind to solubilized receptor molecules within the capsules, and functional ligand binding of both receptors solubilized in DCCcould be 
measured over a period of 15 days (Fig. 4e). In addition, aclear discrimination of GPCR stability in the respective detergent could be measured directly within the capsules. When treated with the harsher detergent DM, capsules containing the less stableNTS 1 -D03 exhibited a loss of HL-NT binding within 10h, whereas the stable receptor $\mathrm{NTS}_{1}-\mathrm{C} 7 \mathrm{E} 02$ bound ligand over the complete 15 day period (Fig. 4e). To our knowledge, this is the first study wheredetergent-solubilized GPCR proteins could be localized, contained and their functional properties assayed within a cell-sized capsule over extended periods of time.

\section{Selection of detergent-stable NTS1 variants}

To verify CHESS as a selection tool in directed evolution experiments, we applied the method to a previously established library known to contain some rare receptor variants that were stable in harsh detergents. The StEPM303 library ${ }^{21}$ is a collection of rNTS $_{1}$ mutants derived from $\mathrm{NTS}_{1}$-D03. This synthetic library comprisesrandom combinations of 33 amino acid substitutionspreviously identified to increase receptor expression and/or stability, recombined with wild-type residues. Thus, at 33 positions in the receptor, there are two possibilities, the mutated or the natural amino acid, and each of the 33 positions can be combined with each other to form a theoretical maximum of $2^{33}\left(=8.6 \times 10^{9}\right)$ possible mutants in this library. It would beimpossible to individually synthesize and screen $8.6 \times 10^{9}$ mutant receptors for stability in detergent. With directed evolution and CHESS, however, we can realistically subject the whole library population to a test of detergent stability so that only the most stable receptors propagate through further generations of selection.

The StEPM303 library was previously applied to the selection for mutants that express high amounts of correctly folded protein located in the inner membrane. ${ }^{21}$. Since there is a correlation between high functional expression and detergent stability, mutants with high 
detergent stability will be strongly enriched in this selected pool. However, still hundreds of mutant receptors from this selected pool were individually screened for stability in shortchain detergents, with only very few, such as $\mathrm{NTS}_{1}$-C7E02, identified.

Because we know that this library contains rare, short-chain detergent stable receptors, it could serve as a test case for CHESS selection, with the aim of screening the full library diversityto directlyisolatereceptors stable in short-chain detergents without relying on the correlation to functional expression level and without the need for extensive additional screening, which was needed to identify $\mathrm{NTS}_{1}-\mathrm{C} 7 \mathrm{E} 02$.

E. coli was transformed with theStEPM303 libraryand expression was induced as previously described ${ }^{21}$.Afterwards, $10^{10}$ cells wereencapsulated and their membranes solubilized withDM for $3 \mathrm{~h}$, followed by a further $2 \mathrm{~h}$ in the presence of fluorescent ligand (BODIPY FL-labelled neurotensin 8-13 (FL-NT)). Approximately 100,000 capsules exhibiting fluorescence signalsthat correspond to the top $0.5-1 \%$ fluorescence of the population were selected with FACS from over $10^{8}$ detected capsules. The receptor-encoding DNAwas amplified from the sorted capsules, re-cloned and transformed for subsequent selection rounds. In the second and third rounds, the very harsh short-chain detergent octyl- $\beta$ D-glucopyranoside (OG) was used to challenge the receptor pool.OG rapidly and efficiently solubilizes E.coli, making the encapsulation step absolutely essential for directed evolution experiments involving this detergent. When re-transformed, expressed and analyzed in parallel with flow cytometry, sequential increases inthe fluorescence intensities of the sorted populations from rounds 1 to 3 were evident, indicatingthat the library population is evolving so that it contains mostly OG-resistant NTS $_{1}$ variants (Fig. 5a). 


\section{High throughput assay for the characterization of solubilized NTS $_{1}$ variants}

The CHESS technology no longer requires growing of individual cultures to testeach mutant separately to identify the detergent-stable ones. Instead, the entire mutant population is subjected to short-chain detergents and in one FACS experiment those mutants are identified which satisfy the stability threshold. Since mutant generation can be carried out iteratively, an entire population can be evolved for detergent stability.

Nonetheless,we wished to determinethe success of the selection by isolating and characterizing someindividual mutants from the final selected population in detail.For this assay, receptors were cloned into an expression vector containing both a C-terminal sfGFP fusion and an avi-tag for in vivo biotinylation. Biotinylation allows the immobilization of solubilized receptor onto streptavidin-coated solid phases such as paramagnetic beads ${ }^{17}$, while fusion of the receptor to sfGFP allows the relative determination of protein loading across many samples by measuring sfGFP fluorescence. Sample handling was automated with a Kingfisher Flex robot, allowing the processing of 96 samples in parallel. Receptor functionality was then measured by binding red fluorescent HL-NT ligand to immobilized, detergent-solubilized receptor variants (Fig. 6).

Twenty-two single clones derived from the final round of $\mathrm{NTS}_{1}$ selection were applied to thisstreamlined IMP stability assay. Briefly, expression cultures were solubilized in $2 \% \mathrm{DM}$ for $3 \mathrm{~h}$ at $20^{\circ} \mathrm{C}$, cell debris removed by centrifugation and the supernatant added to a solution of 20nM HL-NT and streptavidin-coated paramagnetic beads in deep 96-well plates. Biotinylated receptor-bound beads could be magnetically captured and transferred to solutions of $2 \%$ OG containing 20nM HL-NT. Receptor-coated beads were left for $24 \mathrm{~h}$ or $100 \mathrm{~h}$ (4.2 days) after which the beads were captured, washed with $2 \%$ OG containing no ligand and the fluorescence signals corresponding to sfGFP and to ligand bound were 
measured in a fluorescence plate reader. The sfGFP signal enabled us to normalize the samples based on the total amount of receptor present in any particular well.Of the 22 selected library members assayed, 20 exhibited significant ligand binding when solubilized in OG for $2 \mathrm{~h}$, whereas the parental gene, $\mathrm{NTS}_{1}-\mathrm{D} 03$, was completely inactive (Fig. 5b), indicating that the majority of individuals comprising the selected population are in fact OGresistant receptors. Thirteen clones exhibited a significantly increased fraction of functional receptors after $2 \mathrm{~h}$ in OG compared with the previous most stable mutant selected from this library,NTS ${ }_{1}-\mathrm{C} 7 \mathrm{E} 02$. After more than 4 days in OG, 8 clones still displayed significantligand binding, whereas NTS $\mathrm{N}_{1}$ C7E02 did not. It was encouraging that the application of CHESS to the StEPM303 library exceeded our expectations by allowing the isolation of many OGresistant GPCRs, most exhibiting much greater stability than $\mathrm{NTS}_{1}-\mathrm{C} 7 \mathrm{E} 02$.

The assay described above (used there to verify the selection by characterizing individual mutants by a threshold assay) could be easily adapted to determine the thermostability of selected receptors in a semiquantitative way, a commonly used measure of receptor stability.

Typically, such assays involve isolating detergent-solubilized receptor samples, usually in the presence of a labeled ligand to stabilize the receptor, and heating the receptorligand complex at various temperatures for a set time. With increasing temperatures the receptors will denature and release the bound ligands, and this loss of binding can be measured. The level of bound ligand can be plotted against temperature and the temperature at which half of the initial level of bound ligand is observed is called the apparent melting temperature $\left(T_{m}\right)$, or more correctly, since this is an irreversible reaction, $T_{1 / 2}$. However, caution should be used when comparing published $T_{1 / 2}$ values from different studies because $\mathrm{T}_{1 / 2}$ is heavily dependent on the type of detergent used and whether a stabilizing ligand is 
present, in addition to the stability of the receptor. Also, the time of heating plays a role. Thus, only data within one experiment can be compared. Most reported $T_{1 / 2}$ values are determined using receptors solubilised in mild detergents such as DDM, with the receptor heated in the presence of a stabilising ligand. A quantitative comparison between different receptor is thus only possible if the receptors are tested, side by side, in the same assay ${ }^{21}$.

We measured the thermal denaturation profiles of the top 3 selected clones both in the presence or absence of ligand, when solubilized in DM or OG, both being harsh short-chain detergents. NTS ${ }_{1-B}$, NTS $1-G 7$ and NTS $_{1}-$ G8 exhibited enhanced thermal stability over NTS $_{1-}$ C7E02 when heated in the presence or absence of NT in both detergents (Fig. 5c, d, e, f and Table 1). Of particular note was the high stability of these receptors solubilized in OG when heated in the absence of ligand, indicating a high degree of inherent receptor stability. In contrast, no activity could be measured for $\mathrm{NTS}_{1}-\mathrm{C} 7 \mathrm{E} 02$ when solubilized in OG in the absence of the stabilizing ligand.To our knowledge, these are the first published $T_{1 / 2}$ values for a GPCR solubilized in DM or OG in the apo state. From our experience, most receptors require a bound ligand to be stable in such detergents. $\mathrm{NTS}_{1}-\mathrm{B} 5, \mathrm{NTS}_{1}-\mathrm{G} 7$ and $\mathrm{NTS}_{1}-\mathrm{G} 8$ contained22, 21 and 14 amino acid substitutions compared withNTS ${ }_{1}$-D03, respectively, mainly located within the transmembrane helices (Fig. 8a).

It is important to reiterate that the denaturation profiles in Fig. 5c-f only contain data from mutants that have emerged from directed evolution - the precursor of these experiments $\mathrm{NTS}_{1}$-D03 is so unstable under these harsh conditions that it would give no measurable data at all. Even the best mutant from the previous selection for functional expression ${ }^{21}, \mathrm{NTS}_{1}-\mathrm{C} 7 \mathrm{E} 02$, can only be measured in DM (where it is the worst curve), but it gives no measurable data in $\mathrm{OG}$. 


\section{Selection of detergent-stable $\alpha_{1 \mathrm{~A}}-\mathrm{AR}$ variants:}

It was important to demonstrate that CHESS could be applied to other receptors. $\mathrm{NTS}_{1}$ is a peptide receptor, so we chose to test CHESS on a different type of receptor, the $\alpha_{1 A^{-}}$ adrenoceptor $\left(\alpha_{1 \mathrm{~A}}-\mathrm{AR}\right)$, which is activated by the catecholamines adrenaline and noradrenaline. The chosen $\alpha_{1 \mathrm{~A}}$-AR library had previously been subjected to two rounds of error-prone PCR and selection for high functional expression in E.coli ${ }^{17}$. The encapsulated $\alpha_{1 \mathrm{~A}}-\mathrm{AR}$ library was solubilized in situwith the mild detergent mix DCCin the presence of fluorescent ligand (BODIPY-FL-labelled prazosin).FACS was conducted as above for 3 sequential rounds of selection.From the final selected library population, 21 single clones were isolated andwere assayed for increased stability (Fig. 7a). Twelve of these receptors exhibited significantly higher detergent stability than wild-type $\alpha_{1 \mathrm{~A}}$-AR and the most stable mutant identified using selection for higher functional expression with subsequent screening for detergent stability ${ }^{17}, \alpha_{1 \mathrm{~A}}-\mathrm{AR}-05$. The thermal denaturation profiles of the top 4 selected clones were determined when solubilized in DCC. $\alpha_{1 \mathrm{~A}}-\mathrm{AR}-\mathrm{A} 3, \alpha_{1 \mathrm{~A}}-\mathrm{AR}-\mathrm{G} 4, \alpha_{1 \mathrm{~A}}-\mathrm{AR}-\mathrm{D} 7$ and $\alpha_{1 \mathrm{~A}}$-AR-D8exhibited $\mathrm{T}_{1 / 2}$ values of around $40^{\circ} \mathrm{Cwhen}$ heated in the presence of ligand, or around $35^{\circ} \mathrm{Cwhen}$ heated in the absenceof ligand (Fig. $7 \mathrm{~b}, \mathrm{c}$ and Table 2).

When solubilized in DCC in the absence of stabilizing ligand, wild-type $\alpha_{1 \mathrm{~A}}-\mathrm{AR}$ and $\alpha_{1 \mathrm{~A}}$-AR-05were unstable,withno significant fluorescence signal measurable. Thus, Fig. 7 b,conly contain data from mutants that have emerged from directed evolution. Note that in the present study, the receptor is solubilized in the absence of ligand, while in our previous screening method ligand was present during solubilization ${ }^{\frac{17}{}}$, which stabilized $\alpha_{1 \mathrm{~A}}-\mathrm{AR}-\mathrm{wt}$ and $\alpha_{1 \mathrm{~A}}$-AR-05 so that $T_{1 / 2}$ values could be measured. We also would like to reiterate again that the presence or absence of ligand and the nature of the detergent are among the most important parameters determining $T_{1 / 2}$, such that values measured under different experimental conditions cannot be compared. 
The evolved receptors $\alpha_{1 \mathrm{~A}}$-AR-A3, $\alpha_{1 \mathrm{~A}}$-AR-G4, $\alpha_{1 \mathrm{~A}}$-AR-D7 and $\alpha_{1 \mathrm{~A}}$-AR-D8contained between 12 and 14 amino acid substitutions compared to the wild-type receptor(Fig. 8b). All of the selected clones contained substitutions that were not identified in any of the $\alpha_{1 \mathrm{~A}}-\mathrm{AR}$ mutants selected from the same library for high functional expression $\frac{17}{}$, suggesting that CHESS enabled the enrichment of rare mutations that specifically improve receptor stability in detergent, as this property could be directly selected for.

\section{Discussion:}

GPCRs, like many IMPs, are among the most difficult proteins to study in purified form due to their instability in detergents and their inherent conformational heterogeneity. Recently developed crystallization and protein engineering techniques, notably the insertion of a protein into one of the loops, have partly overcome these difficulties with specific receptors, resulting in a flourish of GPCR structures. However, many of the receptors that have been crystallized are closely related to each other, and the methods used requirethat the native protein already has some stability in mild detergents, which is not the case for all GPCRs. The insertion of a protein into intracellular loop 3 will in general preclude interaction with the G proteins and thus abolish signaling.

Purified, stabilized receptors can also be used for drug screening withdirect binding assays and biophysical methods that have previously been impossible to use with GPCRs, since they require purified receptor. Such drug screening platforms bypass the expense and high false-positive hit rates that plague traditional cell-based GPCR HTS assays and would allow GPCRs to be treated like soluble proteins such as enzymes. It is likely that a greater number of compounds can be screened with the isolated proteins than with cell-based HTS assays, and that additional methods such as fragment screening, which require direct physical 
detection of binding, can be applied to such GPCRs. The success of efforts conducting in vitro screening for enzyme inhibitors suggests that the use of solubilized receptors for drug screening might lead to the discoveryof new compound classes and allow more efficient identification of allosteric modulators. Yet, current methods for the engineering of detergentstabilized receptors are insufficient in that they rely on methods such as alanine scanning and screening of individual mutants in isolation, thus severely limiting the sequence space that can be assayed. In the alanine screening approach, positions where the substitution to alanine itself is unfavorable, will be ignored, even though another residue type might be stabilizing.Here we have developed ahigh-throughput method for directlyengineering IMPs that are stable in detergents, whichwill enable structural and screening studies to be applied to a greater proportion of this critically important receptor family.

With CHESS, the conversion ofpopulations of bacterial cells into semipermeable, stable containershas increased the number of mutant receptors that can be simultaneously tested in detergents $10^{5}$ to $10^{6}$ fold, compared to previous methods where individual mutants are tested in separate experiments. Furthermore, because CHESS is an evolutionary method, the testing of combinations of advantageous mutations can be streamlined by recombining the variants contained withinthe selected pools and conducting further rounds of population selection.An essential step in the alanine scanning-based method is to individually synthesize and re-assay combinations of identified mutations, which is unnecessary with CHESS. These characteristics enabled us to rapidly isolate stable GPCR mutants from 2 highly diverse gene libraries over only 3 generations of selection.

It is likely that during CHESS rounds there is some selective pressure on high receptor expression, because we sort based on the absolute fluorescence level of each capsule, however we did not directly test the expression levels of the selected receptors. It is easily possible, however, to combine both methods and to first select a pool for high functional 
expression and then randomize this pool and subject it to CHESS selection. The handling and FACS is similar, and two different traits of the molecules are optimized.

To characterize the most stable receptor mutants contained within the final CHESSselected gene pools in detail, we developed a semi-automated solubilized receptor assay based on immobilizingin vivo biotinylated receptors onto paramagnetic beads ${ }^{17}$, but with the additional incorporation of GFP for normalization. This enabled us to capture, wash, exchange detergents and functionally assay 96 previously selected solubilized receptor samples robotically to identify and compare the stabilities of individual receptor variants.Using this platform, the CHESS-selected NTS $_{1}$ peptide receptor variants were found to exhibit high stability in the short-chain detergent $O G$, which is one of the most successfully used detergents in crystallography of membrane proteins without large exterior domains ${ }^{2}$. However, due to its short alkyl chain, OG is strongly denaturing to most IMPs, yetforms a compact micelle that is thought to maximize the potential forcrystal contacts between the protein molecules. Of the GPCR structures published to date, only dark state rhodopsin was solved in an OG-solubilized form. Using CHESS, we were able to identify several $\mathrm{NTS}_{1}$ mutants that were stable in pure OG micelles for over 4 days. Furthermore, these receptors, solubilized in $\mathrm{OG}$, could be heated to $35-40^{\circ} \mathrm{C}$ for 30 minutes in the presence or absence of ligand before showing loss of activity. This unequivocally makes these receptors some of the most stable ligand-activated GPCR variants engineered to date and highlights the potential of CHESS for generating highly stabilized IMPs. Similarly, CHESSselected catecholamine receptor $\alpha_{1 \mathrm{~A}}$-AR mutants were found to exhibit much higher stability in detergent than wild -type $\alpha_{1 \mathrm{~A}}$-AR and a stabilized mutant that was identified previously ${ }^{17}$.

Theprimary aim of this study was to establish a completely new selection strategy based on single cell encapsulation that would allow testing of a whole library forstability towards detergents. Because it isnot possible to compare $T_{1 / 2}(\mathrm{Tm})$ values between published 
studies it is difficult to definitively state that the CHESS selected $\mathrm{NTS}_{1}$ variants are the most stable GPCRs reported so far. However,it is interesting to point out the differences between the CHESS-selected variants and several other receptors that were stabilized using other methods. In the alanine scanning study by Shibata et.al. ${ }^{16}, 340$ individual NTS mutants were constructed and assayed separately. Identified stabilizing point mutations were then combined to yield a receptor mutant with 4 amino acid changes, NTS1-7m, which was more stable than wild-type $\mathrm{NTS}_{1}$ in a very mild detergent mixture (1\% DDM, 0.6\% CHAPS, $0.12 \%$ CHS, 30\% glycerol). NTS1-7m was not tested in OG-solubilized form and based on the data presented using other detergent mixes is unlikely to be stable enough to withstand this short chain detergent, especially in the absence of ligand. 303OGB5, 3030GG7 and 303OGG8 exhibited unprecedented levels of stability in OG, with $\mathrm{T}_{1 / 2}$ values of around $40^{\circ} \mathrm{C}$ in the presence or absence of ligand (Table 1).

Three other receptors have been stabilized using the same alanine scanning and screening method. The turkey $\beta 1$ adrenoceptor mutant $\beta$ AR-m23 contains 6 mutations and showed low but measurable stability in OG in the presence of ligand $\frac{15}{}$. Reassuringly, despite this low stability in OG, when solubilized in the milder n-octyl- $\beta$-D-thioglucopyranoside, this receptor became the first ligand activated GPCR to be structurally resolved with X-ray crystallography in detergent-solubilized form $\stackrel{24}{*}$. The human A2A adenosine receptor was also stabilized using this method, with the mutants Rag1 and Rant5 also exhibiting low but

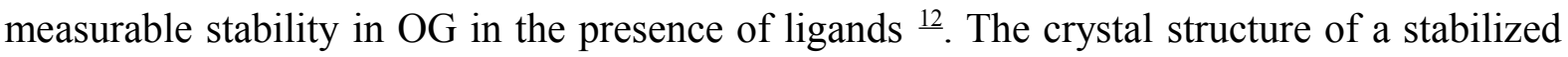
human $\mathrm{A} 2 \mathrm{~A}$ adenosine receptor was recently reported by the same group, however this was a variant containing 4 mutations, called GL-31,with no published stability information $\underline{25}$. Finally, alanine scanning and screening has resulted in a human A2A adenosine receptor and muscarinic $M_{1}$ receptor mutants that exhibit reasonable stability in $\mathrm{OG}$, whenheated in the presence of ligand $\frac{18}{}$. Thus, the CHESS-derived mutants compare very favorably. 
Directed evolution of GPCRs for high functional expression in E.coli has also been a successful method for generating detergent-stable receptors. High expression and stability in detergents seems to correlate reasonably well ${ }^{25}$, as shown for a series of $\mathrm{NTS}_{1}$ mutants tested in different detergents in the presence and absence of ligand.Nonetheless, the most stable $\mathrm{NTS}_{1}$ variant identified from high-expression selections was NTS 1 -C7E02, which we directly compared to the CHESS selected $\mathrm{NTS}_{1}$ mutants in this study. Considering that the CHESS selected $\mathrm{NTS}_{1}$ variants are derived from the same library as $\mathrm{NTS}_{1}-\mathrm{C} 7 \mathrm{E} 02$, their superior stability in short-chain detergents highlights the advantage CHESS confers by enabling the direct selection of receptors for stability in short chain detergents from the full library, as opposed to single mutant screening of a pool preselected for high functional expression.

High expressing clones of the Tachykinin receptor $\mathrm{NK}_{1}, \alpha_{1 \mathrm{~A}}-\mathrm{AR}$ and $\alpha_{1 \mathrm{~B}}-\mathrm{AR}$ also exhibit improved stability in mild long-chain detergent mixes when heated in the presence of stabilizing ligand $\stackrel{17}{ }$. Interestingly, we compared the high expressing $\alpha_{1 \mathrm{~A}}-\mathrm{AR}$ mutant $\alpha_{1 \mathrm{~A}}-\mathrm{AR}$ 0517 to the CHESS selected $\alpha_{1 \mathrm{~A}}-\mathrm{AR}$ mutants and found that when this receptor was solubilized in the absence of ligand, it was unstable, indicating that the CHESS-selected mutants are much more stable than the corresponding high expressing $\alpha_{1 \mathrm{~A}}-\mathrm{AR}$ variants. In contrast, the successful solubilization and subsequent immobilization in the presence of ligand ${ }^{17}$ had previously allowed the stability of $\alpha_{1 \mathrm{~A}}-\mathrm{AR}-05$ and even $\alpha_{1 \mathrm{~A}}$-AR-wt to be characterized. This emphasizes the harshness of solubilization in the absence of ligand. When screening receptors for novel ligands, there should not be a ligand bound already, and thus the selection of GPCRs stable to solubilization in the unliganded state is of great importance.

Computational methods have also been used to identify stabilizing mutations in GPCRs. In a recent study by Chen et al. ${ }^{20}$ the crystal structure of the $\beta 1$ adrenoceptor was computationally analyzed to identify residues that may confer structural instability, which were then mutated and their stability tested. This strategy resulted in mutants that were very 
stable when solubilized in the mild,long-chain detergent DDM. The stability of these receptors in short chain detergents such as OG was not measured, making it difficult to discern how useful they would be for structural and biophysical studies. The large micelle size of DDM makes it unsuitable for the crystallization of GPCRs lacking large solvent exposed domains, with successful vapor diffusion crystallization requiring receptors to be solubilized in short-chain detergents that result in the exposure of more protein surface area to facilitate crystal formation. The stability of a receptor in long chain detergents does not mean that it is stable in short chain detergents. An example of this is that NTS ${ }_{1}-\mathrm{C} 7 \mathrm{E} 02$ exhibiteda similar $T_{1 / 2}$ to the CHESS selected NTS $_{1}$ variants in DM, when heated in the presence of ligand, but $\mathrm{NTS}_{1}$-C7E02 is completely unstable when solubilized in OG without ligand present, whereas the CHESS selected variants are very stable under these conditions (Table 1). Computational methods are also hampered by the fact that they require a crystal structure to make the predictions, which limits their usefulness for acquiring structural information in the first place. Overall, after considering other stabilized receptors in the literature, CHESS enabled the rapid and direct identification of some of the most stable ligand-activated GPCRs reported to date.

The successful application of CHESS to two unrelated GPCRs indicates that CHESS may be ageneric method for generating GPCRs stable in detergents that are excellent candidates not only for crystallographyand NMR but also for direct drug screening methods using solubilized protein.Furthermore, by evolving receptors that are not dependent on fusion of T4 lysozyme into one of the loops, the study of complexes with G-proteins ismade possible ${ }^{29}$. In fact, by modifying the fluorescent components used during CHESS selections, in the future receptor mutants may be directly selected that favor the binding of G-protein mimetics such as peptides ${ }^{30}$ or even the G-proteins themselves, allowing the direct selection of receptors stabilized in active conformations. Here we have demonstrated that CHESS- 
selected IMPs can be immobilized on solid phases and ligand binding to the solubilized receptors can be characterized in an automated, high-throughput manner. Such an assay could be easily adapted to enable the identification of receptor antagonists and agonists from smallmolecule libraries with the purified protein, expanding the discovery space beyond what is possible withcell-based HTS assays. This would in turn lead to a reduction in the costs associated with HTS on IMPs and potentially allow the discovery of less active, but more specific lead compounds for drug development.

Because the permeability of the capsules can be tuned by adding further polyelectrolyte layers, CHESS may be applied to smaller IMPs or soluble proteins such as enzymes. Our method also has many advantages over other compartmentalization methods such as water-in-oil emulsions (reviewed in ref. $\underline{31}$ ), such asproviding access for small molecules from and to the bulk solution, and each compartment is created directly from a bacterial cell. An application such as the one described, in which detergent is used, cannot be carried out with water-in-oil emulsions, nor with intact cells of any kind. All assays that would normally require cell disruption, such as membrane protein solubilization and stability testing, or enzymatic assays with cell-impermeable fluorogenic substrates, can now be carried out directly in these compartments created from live bacterial cells.Additionally, the capsules containing solubilized IMPsmay directly be useable for selection of binding proteins such as antibodies.Finally, because the capsules are stable for weeks, CHESS is also suited to longterm stability studies. In the field of membrane protein study, CHESS may become part of a generic solution to the difficulties associated with IMP instability, in turn leading to a more complete understanding of these therapeutically relevant proteins and thediscovery ofnew molecules with clinical potential. 


\section{Materials and Methods}

Encapsulation of cells. For LbL encapsulation the protocol described by Hillberg et al. $\underline{27}$ was followed with the following modifications: cells were harvested after protein expression by centrifuging at $3800 \mathrm{rcf}$ in a swinging bucket centrifuge and washed 3 times with Phosphate Buffered Saline (PBS) pH 7.4, 1 mM EDTA and $25 \mu \mathrm{g} / \mathrm{ml}$ chloramphenicol (PBSE). Cells were resuspended in PBS-E, pH 6.0 , containing $0.25 \mathrm{mg} / \mathrm{ml}$ low molecular weight chitosan (Sigma Aldrich) and mixed vigorously for 20 minutes. Cells were collected by centrifuging at $1700 \mathrm{rcf}$ in a swinging bucket centrifuge and washed 3 times with PBS-E pH 6.0 before being resuspended in PBS-E pH 6.0 containing $0.25 \mathrm{mg} / \mathrm{ml}$ low viscosity alginic acid (Sigma Aldrich) and subjected to 20 min of vigorous shaking. Capsules were washed 3 times in PBS-E $\mathrm{pH} 6.0$ and finally resuspended in PBS-E $\mathrm{pH}$ 7.4. The particulate and fluorescent properties of encapsulated samples were characterized using a PartecCyFlow Space cytometer with volumetric particle counting capability. For assessment of the detergent resistance of nanocapsules, samples were treated with PBS-E containing $1 \%$ dodecyl- $\beta$-Dmaltopyranoside (DDM) and $\quad 0.5 \% \quad 3$-[(3-cholamidopropyl)-dimethylammonio]-1propanesulfonate/N,N-dimethyl-3-sulfo-N-[3-[[3 $\alpha, 5 \beta, 7 \alpha, 12 \alpha)-3,7,12$-trihydroxy-24-

oxocholan-24-yl]amino]propyl]-1-propanaminium hydroxide (CHAPS). In ligand binding assays measured with FACS, bacterial cells were exposed to $20 \mathrm{nM}$ HiLyte Fluor 647 labelled neurotensin (8-13) (HL-NT) (synthesized by Anaspec) for at least $2 \mathrm{~h}$ before being centrifuged and washed once before FACS analysis. For assessing the stability of known receptors when solubilized in nanocapsules, the mild detergent mix used was made up of PBS-E containing 1\% DDM, 0.5\% CHAPS, 0.1\% cholesteryl hemisuccinate Tris salt (CHS), 
(termed PBS-E(DCC)). The harsher detergent used was PBS-E containing $1.7 \%$ decyl- $\beta$-Dmaltopyranoside (DM), termed PBS-E(DM).

Transmission electron microscopy. Samples were centrifuged in Eppendorf tubes and the supernatant was discarded. Cells or nanocapsules from the pellet were drawn into cellulose capillary tubes and immediately immersed in 1-hexadecene to prevent drying. Tubes of about $4 \mathrm{~mm}$ length were cut using a scalpel and transferred into the $150 \mu \mathrm{m}$ well of a $6 \mathrm{~mm}$ aluminium specimen carrier. Treated E. coli cultures were centrifuged in sealed $200 \mu 1$ pipette tips. The supernatant was removed with filter paper, the sealed tip cut off and the pellet directly pipetted into the $100 \mu \mathrm{m}$ cavity of a $6 \mathrm{~mm}$ aluminium specimen carrier. Samples were sandwiched with a flat $6 \mathrm{~mm}$ aluminium specimen carrier dipped in 1hexadecene and high-pressure frozen with an EM HPM100 high-pressure freezer (Leica Microsystems, Vienna, Austria). The samples were freeze-substituted with anhydrous acetone containing 2\% $\mathrm{OsO}_{4}$ in an AFS2 freeze-substitution unit (Leica Microsystems). Samples were substituted for $8 \mathrm{~h}$ at $-90^{\circ} \mathrm{C}, 8 \mathrm{~h}$ at $-60^{\circ} \mathrm{C}, 8 \mathrm{~h}$ at $-30^{\circ} \mathrm{C}$, and $1 \mathrm{~h}$ at $0^{\circ} \mathrm{C}$ with periodic temperature transition gradients of $30^{\circ} \mathrm{C} / \mathrm{h}$. Samples were then washed twice with anhydrous acetone at $4^{\circ} \mathrm{C}$ and embedded in Epon/Araldite. Sections were post-stained with uranyl acetate and lead citrate and imaged in a Phillips CM 12 transmission electron microscope (FEI, Eindhoven, Netherlands) using a Gatan CCD camera $(1 \mathrm{k} \times 1 \mathrm{k}$ pixels $)$ and digital micrograph acquisition software (Gatan GmbH, Munich, Germany).

Selection of detergent-stable GPCRs from libraries. E. coli cultures transformed with GPCR libraries were encapsulated and treated with PBS-E pH 7.4 containing complete protease inhibitors (Roche), $25 \mu \mathrm{g} / \mathrm{ml}$ chloramphenicol and 2\% DM (PBS-E(DM)). For selections with the StEPM303 library, the initial selection round involved challenging the encapsulated naïve library with $2 \% \mathrm{DM}$ for $3 \mathrm{~h}$ at $20^{\circ} \mathrm{C}$ with vigorous shaking without ligand, followed by $2 \mathrm{~h}$ at $20^{\circ} \mathrm{C}$ in the presence of $20 \mathrm{nM}$ BODIPY FL labeled NT(8-13) (FL- 


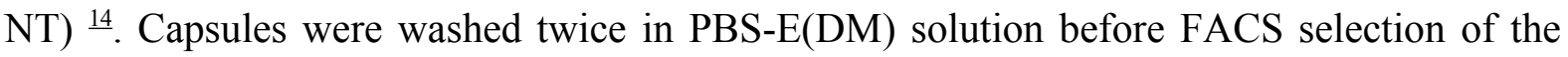
top $0.5-1 \%$ fluorescent capsules in the FITC channel using a FACSAria III cell sorter (BD Biosciences). Genetic information was recovered from the sorted capsules by PCR amplification using specific primers after ultrasonic disruption of the capsules in an ultrasonic water bath for 5 minutes. Amplified DNA was re-cloned into the expression vector and $E$. coli was transformed again. Upon transformation, care was taken to ensure that the number of transformants generated was always at least twice that of the number of selected capsules to minimize the loss of selected individuals.In the second and third rounds of selection, the capsules were solubilized in PBS-E(DM) as in the first round for $3 \mathrm{~h}$, followed by addition of $20 \mathrm{nM}$ FL-NT for $1 \mathrm{~h}$, before the capsules were collected by centrifugation and resuspended in PBS-E containing 2\% octyl- $\beta$-D-glucopyranoside (OG) (PBS-E(OG)) and 20 nM FL-NT. Capsules were washed once in 20 nM FL-NT in PBS-E(OG) to promote efficient detergent exchange before being incubated for $2 \mathrm{~h}$ in $2 \%$ OG with ligand. Capsules were washed twice in PBS-E(OG) and the top $0.5-1 \%$ of the fluorescent capsules sorted with FACS.

For $\alpha_{1 \mathrm{~A}}$-AR library selections, 3 rounds of selection were undertaken with solubilization in PBS-E(DCC) containing 200 nM BODIPY-FL-prazosin (Invitrogen). Capsules were washed twice in PBS-E(DCC) and the top $0.5-1 \%$ of the fluorescent capsules sorted with FACS.

Screening selected clones for detergent stability. Selected receptors were expressed with a C-terminal sfGFP-AviTag fusion. Receptors were expressed in 24-deep-well plates and the cells solubilized in PBS-E(DM) containing $50 \mathrm{mg} / \mathrm{ml}$ chicken lysozyme (Sigma Aldrich). Plates were subjected to 5 min of sonication in an ultrasonic water bath before incubation for $3 \mathrm{~h}$ at $20^{\circ} \mathrm{C}$ with vigorous shaking. Cell debris was removed and the supernatant containing solubilized receptor incubated with streptavidin-coated paramagnetic beads (Invitrogen) and in the case of $\mathrm{NTS}_{1}$ variants, $20 \mathrm{nM}$ HL-NT for $1 \mathrm{~h}$ at $4{ }^{\circ} \mathrm{C}$. Solutions were mixed and the beads manipulated in 96-deep-well plates with a Kingfisher FLEX magnetic particle 
processor (Thermo Scientific). For the $\mathrm{NTS}_{1}$ mutants, receptor-coated beads were transferred into 2 subsequent detergent exchange solutions of PBS-E(OG) containing $20 \mathrm{nM}$ HL-NT. After $2 \mathrm{~h}$ or $100 \mathrm{~h}$ exposure to OG, beads were washed once in PBS-E(OG), before being transferred to clear bottom, black 96-well microplates (Greiner) in $100 \mu 1$ PBS-E(OG) per well. HL-NT and sfGFP fluorescence levels were measured in each well using an M1000 dual monochromator fluorescence plate reader (Tecan), with excitation at $630 \mathrm{~nm}$ for HL-NT and $488 \mathrm{~nm}$ for sfGFP. The fluorescence emission signal at $668 \mathrm{~nm}$ was measured for HL-NT and $512 \mathrm{~nm}$ for sfGFP.

For single $\alpha_{1 \mathrm{~A}}-\mathrm{AR}$ clone analysis ${ }^{3} \mathrm{H}$-labelled prazosin (PerkinElmer) was used for quantitating ligand binding to solubilized receptors. Expression and solubilization was carried out in PBS-E(DCC), further supplemented with $30 \%$ glycerol, $50 \mathrm{mg} / \mathrm{ml}$ chicken lysozyme and $20 \mathrm{nM}\left[{ }^{3} \mathrm{H}\right]$ prazosin at $20^{\circ} \mathrm{C}$. After binding to magnetic beads and washing, $3 / 4$ of the final bead solution per data point $(15 \mu \mathrm{l})$ was resuspended in $200 \mu \mathrm{l}$ of OptiPhaseSupermix cocktail (PerkinElmer) and the ${ }^{3} \mathrm{H}$ counts measured on a liquid scintillation counter (1450 Microbeta plus; PerkinElmer). The remaining $1 / 4$ of bead solution was resuspended in $100 \mu 1$ PBS-E(DCC), 30\% glycerol, and the sfGFP fluorescence of each sample measured as above.

Thermal stability assays. $\mathrm{NTS}_{1}$ mutants were expressed in $200 \mathrm{ml}$ cultures for $20-24 \mathrm{~h}$ at $20^{\circ} \mathrm{C}$. Cells were harvested with centrifugation, washed once with PBS-E and the cells disrupted with sonication (Sonifier 250, Branson). Lysed cells were collected with centrifugation and the supernatant discarded. The pellet was solubilized in PBS-E(DM) containing $50 \mathrm{mg} / \mathrm{ml}$ chicken lysozyme at $20^{\circ} \mathrm{C}$ with vigorous shaking for $3 \mathrm{~h}$. Insoluble material was removed by centrifugation and the supernatant exposed to streptavidin-coated paramagnetic beads. Solubilized receptor was allowed to bind to the beads for $1 \mathrm{~h}$ at $4{ }^{\circ} \mathrm{C}$ before being transferred to new vessels containing either PBS-E(DM) or PBS-E(OG) without ligand and mixed for $15 \mathrm{~min}$. Beads were resuspended into new vessels containing either 
PBS-E(DM) or PBS-E(OG), with or without ligand (or competitor). Bead-containing solutions were distributed along rows of 96-well PCR plates and subjected to $30 \mathrm{~min}$ of heat treatment using a gradient PCR cycler (Biometra). Ligands were incubated with receptorcoated beads for $1.5 \mathrm{~h}$ before or after heating. Beads were washed once in the relevant detergent solution before being resuspended in clear bottom, black 96-well-microplates and the residual fluorescence intensities of each well measured as above. Apparent $T_{1 / 2}$ values were defined using non-linear regression fitting of the data with GraphPad Prism.

For $\alpha_{1 \mathrm{~A}}-\mathrm{AR}$ variants, expression and sonication was conducted as above, but the pellet was solubilized in PBS-E(DCC) containing $50 \mathrm{mg} / \mathrm{ml}$ chicken lysozyme and 30\% glycerol at $20^{\circ} \mathrm{C}$ with vigorous shaking for $3 \mathrm{~h}$ in the absence of ligand. Heat and ligand treatment was performed as above, with the radioligand binding assay and curve fitting performed as described previously ${ }^{17}$.

\section{Acknowledgments}

We acknowledge the professional help given by the staff of the Center for Microscopy and Image Analysis at the University of Zurich, where all FACS and microscopy were performed, particularly VinkoTosevski, Claudia Dumrese and Andres Kaech. This work was supported by a C.J. Martin Biomedical Overseas Fellowship from the National Health and Medical Research Council of Australia and a postdoctoral fellowship from the Forschungskredit of the University of Zurich, both to D.J.S., and by the NCCR Structural Biology (to A.P.).

\section{References}

1. Salon, J. A., Lodowski, D. T. \& Palczewski, K. (2011). The significance of G proteincoupled receptor crystallography for drug discovery. Pharmacol. Rev.63, 901-37.

2. Prive, G. G. (2007). Detergents for the stabilization and crystallization of membrane proteins. Methods41, 388-97. 
3. Tate, C. G. \& Schertler, G. F. (2009). Engineering G protein-coupled receptors to facilitate their structure determination. Curr. Opin. Struc. Biol.19, 386-95.

4. Deber, C. M., Khan, A. R., Li, Z., Joensson, C., Glibowicka, M. \& Wang, J. (1993). Val-->Ala mutations selectively alter helix-helix packing in the transmembrane segment of phage M13 coat protein. Proc. Natl. Acad. Sci. U. S. A.90, 11648-52.

5. Cortes, D. M. \& Perozo, E. (1997). Structural dynamics of the Streptomyces lividans $\mathrm{K}+$ channel (SKC1): oligomeric stoichiometry and stability. Biochemistry36, 1034352.

6. Perozo, E., Cortes, D. M. \& Cuello, L. G. (1998). Three-dimensional architecture and gating mechanism of a $\mathrm{K}+$ channel studied by EPR spectroscopy. Nat. Struct. Biol.5, 459-69.

7. Lau, F. W., Nauli, S., Zhou, Y. \& Bowie, J. U. (1999). Changing single side-chains can greatly enhance the resistance of a membrane protein to irreversible inactivation. J. Mol. Biol.290, 559-64.

8. Wang, C. \& Deber, C. M. (2000). Peptide mimics of the M13 coat protein transmembrane segment. Retention of helix-helix interaction motifs. J. Biol. Chem.275, 16155-9.

9. Zhou, Y. \& Bowie, J. U. (2000). Building a thermostable membrane protein. J. Biol. Chem.275, 6975-9.

10. Bowie, J. U. (2001). Stabilizing membrane proteins. Curr. Opin. Struct. Biol.11, 397402.

11. Standfuss, J., Xie, G., Edwards, P. C., Burghammer, M., Oprian, D. D. \& Schertler, G. F. (2007). Crystal structure of a thermally stable rhodopsin mutant. J. Mol. Biol.372, 1179-88.

12. Magnani, F., Shibata, Y., Serrano-Vega, M. J. \& Tate, C. G. (2008). Co-evolving stability and conformational homogeneity of the human adenosine A2a receptor. Proc. Natl. Acad. Sci. U. S. A.105, 10744-9.

13. Roth, C. B., Hanson, M. A. \& Stevens, R. C. (2008). Stabilization of the human beta2-adrenergic receptor TM4-TM3-TM5 helix interface by mutagenesis of Glu122(3.41), a critical residue in GPCR structure. J. Mol. Biol.376, 1305-19.

14. Sarkar, C. A., Dodevski, I., Kenig, M., Dudli, S., Mohr, A., Hermans, E. \&Plückthun, A. (2008). Directed evolution of a $\mathrm{G}$ protein-coupled receptor for expression, stability, and binding selectivity. Proc. Natl. Acad. Sci. U. S. A.105, 14808-13.

15. Serrano-Vega, M. J., Magnani, F., Shibata, Y. \& Tate, C. G. (2008). Conformational thermostabilization of the beta1-adrenergic receptor in a detergent-resistant form. Proc. Natl. Acad. Sci. U. S. A.105, 877-82.

16. Shibata, Y., White, J. F., Serrano-Vega, M. J., Magnani, F., Aloia, A. L., Grisshammer, R. \& Tate, C. G. (2009). Thermostabilization of the neurotensin receptor NTS1. J. Mol. Biol.390, 262-77.

17. Dodevski, I. \&Plückthun, A. (2011). Evolution of three human GPCRs for higher expression and stability. J. Mol. Biol.408, 599-615.

18. Robertson, N., Jazayeri, A., Errey, J., Baig, A., Hurrell, E., Zhukov, A., Langmead, C. J., Weir, M. \& Marshall, F. H. (2011). The properties of thermostabilised G proteincoupled receptors (StaRs) and their use in drug discovery. Neuropharmacology60, 3644.

19. Schlinkmann, K. M., Honegger, A., Tureci, E., Robison, K. E., Lipovsek, D. \&Plückthun, A. (2012). Critical features for biosynthesis, stability, and functionality of a $\mathrm{G}$ protein-coupled receptor uncovered by all-versus-all mutations. Proc. Natl. Acad. Sci. U. S. A.109, 9810-5. 
20. Chen, K. Y., Zhou, F., Fryszczyn, B. G. \& Barth, P. (2012). Naturally evolved G protein-coupled receptors adopt metastable conformations. Proc. Natl. Acad. Sci. U. S. A.109, 13284-9.

21. Schlinkmann, K. M., Hillenbrand, M., Rittner, A., Kunz, M., Strohner, R. \&Plückthun, A. (2012). Maximizing detergent stability and functional expression of a GPCR by exhaustive recombination and evolution. J. Mol. Biol.422, 414-28.

22. Zhukov, A., Andrews, S. P., Errey, J. C., Robertson, N., Tehan, B., Mason, J. S., Marshall, F. H., Weir, M. \& Congreve, M. (2011). Biophysical mapping of the adenosine A2A receptor. J. Med. Chem.54, 4312-23.

23. Congreve, M., Rich, R. L., Myszka, D. G., Figaroa, F., Siegal, G. \& Marshall, F. H. (2011). Fragment screening of stabilized G-protein-coupled receptors using biophysical methods. Method. Enzymol.493, 115-36.

24. Warne, T., Serrano-Vega, M. J., Baker, J. G., Moukhametzianov, R., Edwards, P. C., Henderson, R., Leslie, A. G., Tate, C. G. \& Schertler, G. F. (2008). Structure of a beta1-adrenergic G-protein-coupled receptor. Nature454, 486-91.

25. Lebon, G., Warne, T., Edwards, P. C., Bennett, K., Langmead, C. J., Leslie, A. G. \& Tate, C. G. (2011). Agonist-bound adenosine A2A receptor structures reveal common features of GPCR activation. Nature474, 521-5.

26. Diaspro, A., Silvano, D., Krol, S., Cavalleri, O. \& Gliozzi, A. (2002). Single Living Cell Encapsulation in Nano-organized Polyelectrolyte Shells. Langmuir18, 4.

27. Hillberg, A. L. \& Tabrizian, M. (2006). Biorecognition through layer-by-layer polyelectrolyte assembly: in-situ hybridization on living cells. Biomacromolecules 7 , 2742-50.

28. Yuan, W., Dong, H., Li, C. M., Cui, X., Yu, L., Lu, Z. \& Zhou, Q. (2007). pHcontrolled construction of chitosan/alginate multilayer film: characterization and application for antibody immobilization. Langmuir 23, 13046-52.

29. Rasmussen, S. G., DeVree, B. T., Zou, Y., Kruse, A. C., Chung, K. Y., Kobilka, T. S., Thian, F. S., Chae, P. S., Pardon, E., Calinski, D., Mathiesen, J. M., Shah, S. T., Lyons, J. A., Caffrey, M., Gellman, S. H., Steyaert, J., Skiniotis, G., Weis, W. I., Sunahara, R. K. \& Kobilka, B. K. (2011). Crystal structure of the beta2 adrenergic receptor-Gs protein complex. Nature477, 549-55.

30. Scheerer, P., Park, J. H., Hildebrand, P. W., Kim, Y. J., Krauss, N., Choe, H. W., Hofmann, K. P. \& Ernst, O. P. (2008). Crystal structure of opsin in its G-proteininteracting conformation. Nature455, 497-502.

31. Griffiths, A. D. \& Tawfik, D. S. (2006). Miniaturising the laboratory in emulsion droplets. Trends. Biotechnol.24, 395-402. 


\section{FigureLegends:}

Fig. 1. Schematic representation of the CHESS method. A library of receptor mutants (a) is transformed and expressed in the inner membrane of $E$. coli(b). Cells are encapsulated (c) and the cell membrane permeabilized with detergent (d), leading to a solubilization of the receptor. The encapsulation layer serves as a semi-permeable barrier, retaining the solubilized receptor and its encoding plasmid within the capsule, but allowing fluorescently labelled ligand into the capsule, where it can bind to functional receptor molecules (e). Capsules containing detergent-stable GPCR mutants are more fluorescent and can be sorted from the population with FACS (f). Genetic material is recovered from the sorted capsules (g) and used to either identify desired receptor mutants or serve as a template for further rounds of mutation or selection $(\mathbf{h})$.

Fig. 2. Layer by layer (LbL) encapsulation of E.coli cells. (a-c) E. coli cells were encapsulated by laying down alternate layers of positively charged chitosan polymer and negatively charged alginate.Encapsulated cells were analyzed with transmission electron microscopy. (d) Electron micrographs of naked E. coli cells, (e), encapsulated cells and (f), encapsulated cells treated with 1\% DDM (dodecyl- $\beta$-D-maltopyranoside) for $24 \mathrm{~h}$.

Fig. 3. Optimization of LbL encapsulation of single E. coli cells. (a), The amount of aggregated cells produced during the LbL process could be greatly reduced by the addition of $1 \mathrm{mM}$ EDTA to the encapsulation solutions. (b), Reducing the $\mathrm{pH}$ of the encapsulation solutions below 7 resulted in stronger capsules that were able to resist detergent treatment.

Fig. 4. Encapsulation of cells and characterization of resultant nanocapsules. GPCRexpressing E. coli cells were encapsulated with 1 layer of chitosan and 1 layer of alginate in 
triplicate and analyzed with flow cytometry. (a) The laser scattering properties of the naked cells allowed the definition of a gate that enclosed $100 \%$ single cells. (b) $66 \%$ of particles detected in the encapsulated cell sample fell within this singlecell gate, with most of the remaining particles exhibiting scattering properties characteristic of larger particles. (c) Naked and encapsulated cells were exposed to detergent (1\% DDM, 0.5\% CHAPS, 0.1\% CHS) and the loss of cell-like particles over time assayed with FACS. Detergent treatment of naked cells resulted in a rapid loss of cell-like particles (black open circles), whereas the detergent-treated encapsulated cell sample (red open squares) maintained a high proportion of cell-like particles over the 15-day period. Untreated naked cells (black solid circles) and untreated encapsulated cells (red solid squares) both maintained a high proportion of cell-like particles over time. (d)C-terminally sfGFP-tagged NTS $_{1}$-D03- and NTS $_{1}$-C7E02-expressing cells were encapsulated and exposed to a mild detergent mixture (DCC) or harsh detergent (DM) in the presence of HL-NT. The sfGFP fluorescence contained within the capsules was measured using flow cytometryperiodically for 15 days. No significant reduction in the mean fluorescence intensity (MFI) in the sfGFP channel was observed in the samples, indicating that the expressed receptors did not leak out of the capsules. (e) Conversely, the average level of bound ligand per capsule varied more over the 15 day experiment. As expected, theligand binding activity of $\mathrm{NTS}_{1}-\mathrm{D} 03$ in DM is reduced over time, while the more stable $\mathrm{NTS}_{1}$ C7E02 remains active. The fluorescence of the $\mathrm{NTS}_{1}$-C7E02 samples tended to increase over the first 2 days before returning to the initial level after 15 days, indicating that this mutant was able to bind ligand over the course of the experiment.

Fig. 5. Selection of detergent-stable $\mathrm{NTS}_{1}$ mutants with CHESS. Detergent-stable StEPM303 library members were selected with FACS using 20 nM FL-NT. (a) Fluorescence histograms of the sorted populations revealing strong enrichment of detergent-stable receptors. (b) 22 selected clones were expressed individually, solubilized and assayed for ligand binding 
activity after 2 or $100 \mathrm{~h}$ in OG. (c)To test the stability in DM, the top 3 receptors were expressed and solubilized in $1.7 \% \mathrm{DM}$ for $3 \mathrm{~h}$ at $20^{\circ} \mathrm{C}$. Solubilized receptors were bound to streptavidin-coated paramagnetic beads at $4^{\circ} \mathrm{C}$ for $1 \mathrm{~h}$ in the absence of ligand. NTS $-\mathrm{C} 7 \mathrm{E} 02$ (black circles), $\mathrm{NTS}_{1}-\mathrm{B} 5$ (red squares), $\mathrm{NTS}_{1}-\mathrm{G} 7$ (blue circles) orNTS 1 -G8 (green triangles) coated beads were treated with either $20 \mathrm{nM}$ HL-NT(8-13) in $1.7 \% \mathrm{DM}$ for $1 \mathrm{~h}$ before being thermally challenged for $30 \mathrm{~min}$ at increasing temperatures or (d) heated in the absence of ligand and thentreated with $20 \mathrm{nM}$ HL-NT(8-13). (e) Alternatively, to test the stability in OG, after initial solubilization in $1.7 \% \mathrm{DM}$, receptor-coated beads were washed for $15 \mathrm{~min}$ in $2 \%$ $\mathrm{OG}$ at $4{ }^{\circ} \mathrm{C}$ without ligand before being either exposed to $20 \mathrm{nM}$ HL-NT(8-13) in $2 \%$ OG for $1 \mathrm{~h}$ and then being thermally challenged for $30 \mathrm{~min}$ at increasing temperatures or (f) heated in the absence of ligand and then treated with 20 nM HL-NT(8-13). No specific signal could be measured from $\mathrm{NTS}_{1}$-C7E02-coated beads in 2\% OG. Parallel measurements were taken at every temperature point in the presence of $5 \mu \mathrm{MNT}(8-13)$ as a competitor to determine the specific fluorescence signal. Data points are plotted as the mean of duplicate measurements, $100 \%$ represents the signal measured after heating at $20^{\circ} \mathrm{C}$ for $30 \mathrm{~min}$. Error bars indicate the standard error of the mean.

Fig. 6.Fluorescence based screening of selected GPCR variants. (a) Selected GPCR clones are inserted into a screening vector (b) comprising an N-terminal maltose binding protein fusion and a C-terminal sfGFP and Avi-tag fusion. E. coli are transformed with the resultant constructs and individual clones expressed separately. The bacteria biotinylate the Avi-tag in vivo (c). The cells are solubilized with detergent and the biotin-tagged receptors captured onto streptavidin coated paramagnetic beads (d). Beads are washed and exposed to red fluorescently labeled GPCR ligand in an automated fashion using a Kingfisher ${ }^{\mathrm{TM}}$ magnetic particle processor. (e) The sfGFP and red ligand fluorescence associated with the beads is 
measured in a fluorescence plate reader to determine the amount of receptor protein bound to the beads and whether the solubilized receptor can bind to fluorescent ligand.

Fig. 7. Selection of detergent-stable $\alpha_{1 \mathrm{~A}}$-AR mutants with CHESS. Detergent-stable $\alpha_{1 \mathrm{~A}}$-AR library members were selected with FACS using $200 \mathrm{nM}$ BODIPY FL prazosin. (a) 21 selected clones were expressed individually, solubilized and assayed for ligand-binding activity after 3 hours in PBS-E(DCC). (b) The top 4 receptors were solubilized in PBS$\mathrm{E}(\mathrm{DCC})$ for $3 \mathrm{~h}$ at $20^{\circ} \mathrm{C}$ in the absence of ligand. Solubilized receptors were captured from the supernatant with streptavidin paramagnetic beads at $4^{\circ} \mathrm{C}$ for 1 h. $\alpha_{1 \mathrm{~A}}-\mathrm{AR}^{\mathrm{A} 3}$ (black circles), $\alpha_{1 \mathrm{~A}}-\mathrm{AR}^{\mathrm{G} 4}$ (red open squares), $\alpha_{1 \mathrm{~A}}-\mathrm{AR}^{\mathrm{D} 7}$ (blue crosses) or $\alpha_{1 \mathrm{~A}}-\mathrm{AR}^{\mathrm{D} 8}$ (green open circles) coated beads were either treated with $20 \mathrm{nM}\left[{ }^{3} \mathrm{H}\right]$ prazosin for $1 \mathrm{~h}$ before being thermally challenged for $30 \mathrm{~min}$ at increasing temperatures or (c)heated in the absence of ligand and then treated with $20 \mathrm{nM}\left[{ }^{3} \mathrm{H}\right]$ prazosin. Note that no curves can be shown for the (wt) $\alpha_{1 \mathrm{~A}}-\mathrm{AR}-(\mathrm{wt})$ and the previously selected high-expressing mutant $\alpha_{1 \mathrm{~A}}-\mathrm{AR}^{05}$, since no significant signal could be measured from them when the receptors were solubilized in the absence of ligand, indicating that they lose all activity. They can only be solubilized in the presence of ligand ${ }^{17}$.Parallel measurements were taken for every receptor in the presence of $10 \mu \mathrm{M}$ unlabeled prazosin as a competitor to determine the specific fluorescence signal. Data points are plotted as the mean of duplicate measurements, $100 \%$ represents the signal measured after heating at $20^{\circ} \mathrm{C}$ for 30 min. Error bars indicate the standard error of the mean.

Fig. 8. Sequence alignments of the most stable $\mathrm{NTS}_{1}$ and $\alpha_{1 \mathrm{~A}}-\mathrm{AR}$ selected variants. (a) Sequences of selected $\mathrm{NTS}_{1}$ mutants. The amino acid sequences of the selected receptors

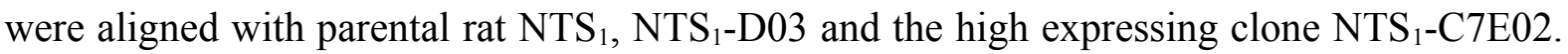
Positions 183 and 313 were not part of the designed library but mutations due to PCR errors. (b) Sequences of selected $\alpha_{1 \mathrm{~A}}-\mathrm{AR}$ mutants. The amino acid sequences of the selected 
receptors were aligned with parental $\alpha_{1 \mathrm{~A}}-\mathrm{AR}$ and the previously identified high expressing mutant $\alpha_{1 \mathrm{~A}}-\mathrm{AR}^{05}$. Locations of the transmembrane helices are indicated with cylinders whereas the number of amino acid mutations over parental proteins are shown in the $\Delta$ column. 
Table 1. Apparent $\mathrm{T}_{1 / 2}\left({ }^{\circ} \mathrm{C}\right)$ in harsh detergents in the absence or presence of ligand

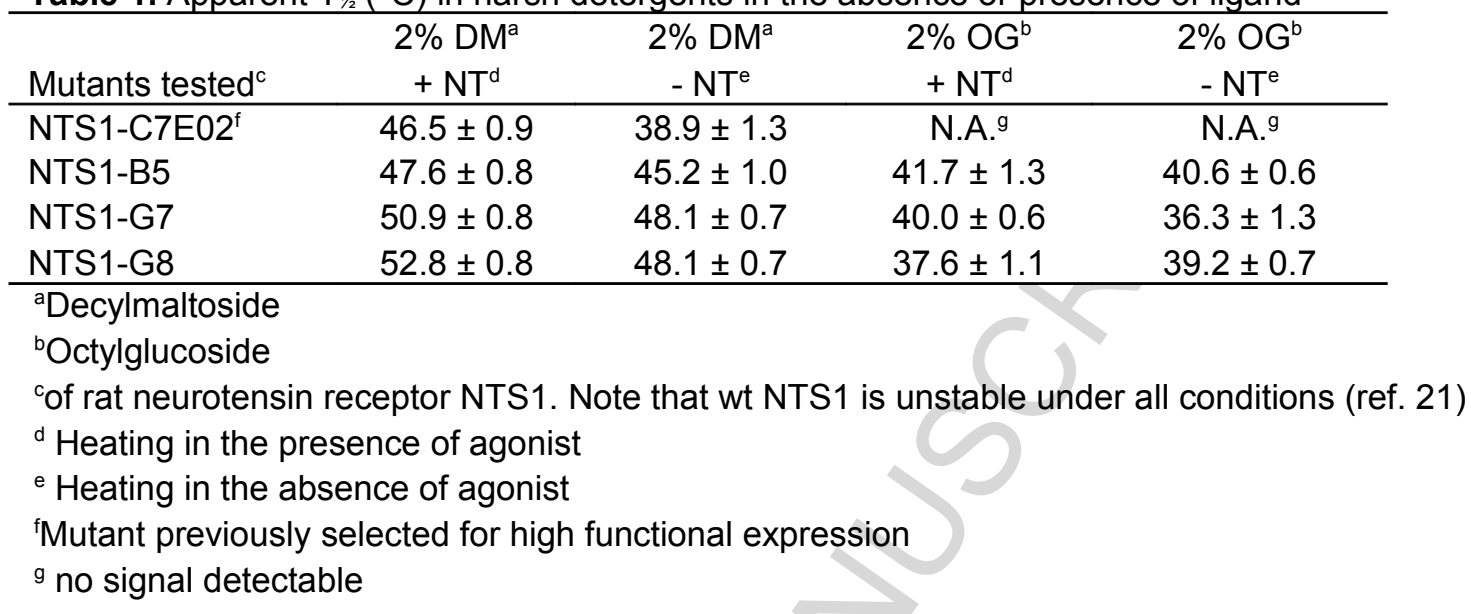


(a)

Receptor Library (b)

Expression in cells

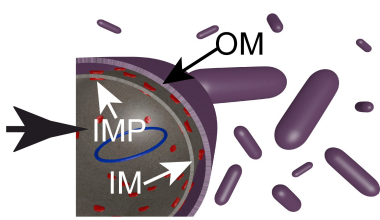

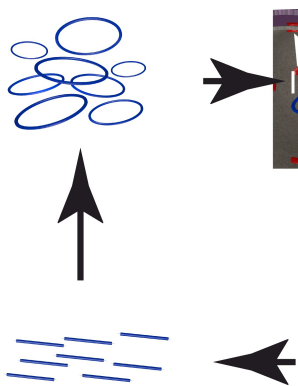

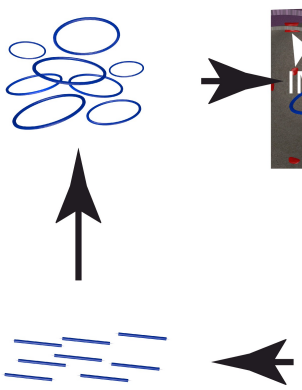

(h)

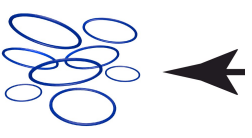

(g)

(c)

Encapsulation of the cells

(d)

Solubilization

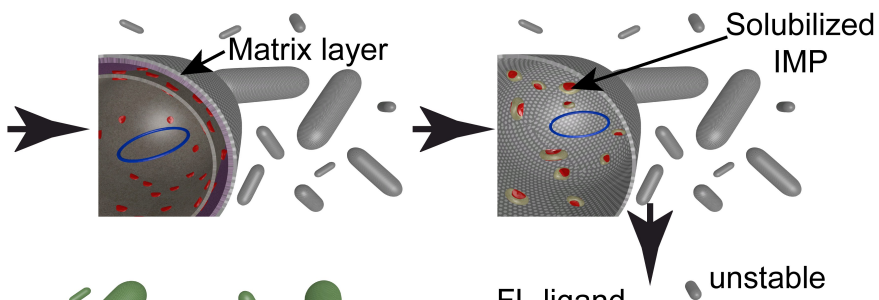$$
\text { (1) }
$$

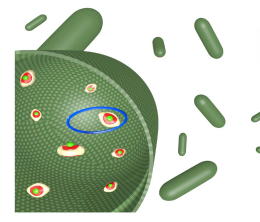

(f)

Capsules containing stable receptors enriched with FACS $\begin{array}{rr}\text { Genes amplified with PCR } & \text { DNA extracted from } \\ \text { (additional mutagenesis can } & \text { sorted capsules }\end{array}$ be applied at this point) 

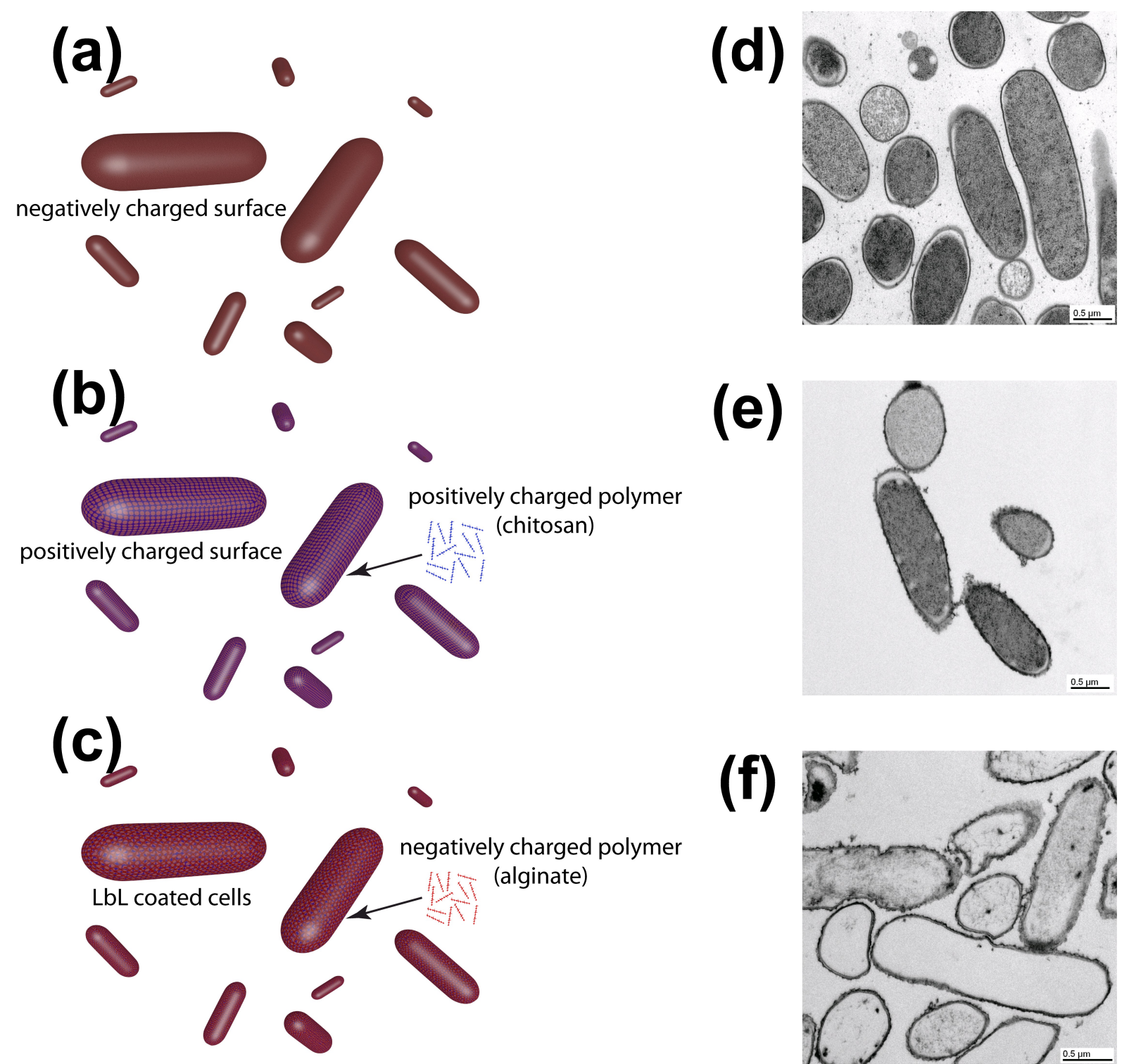

(e)

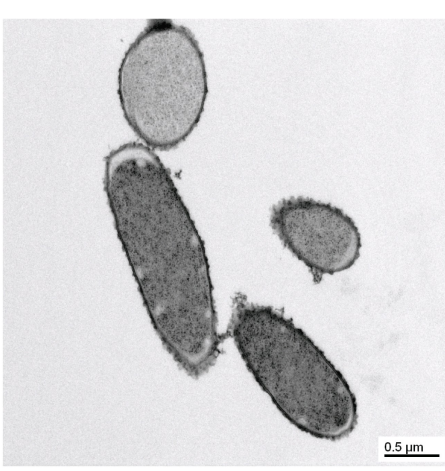

(f)

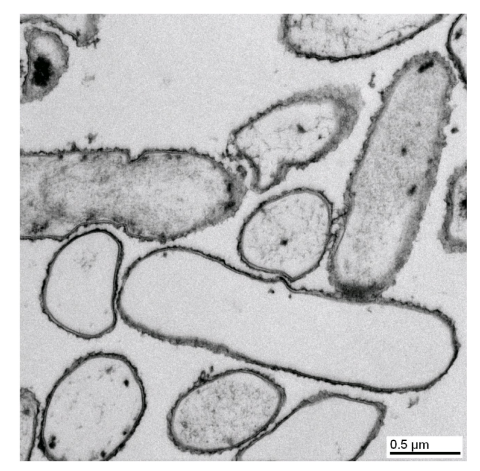


ACCEPTED MANUSCRIPT

(a)

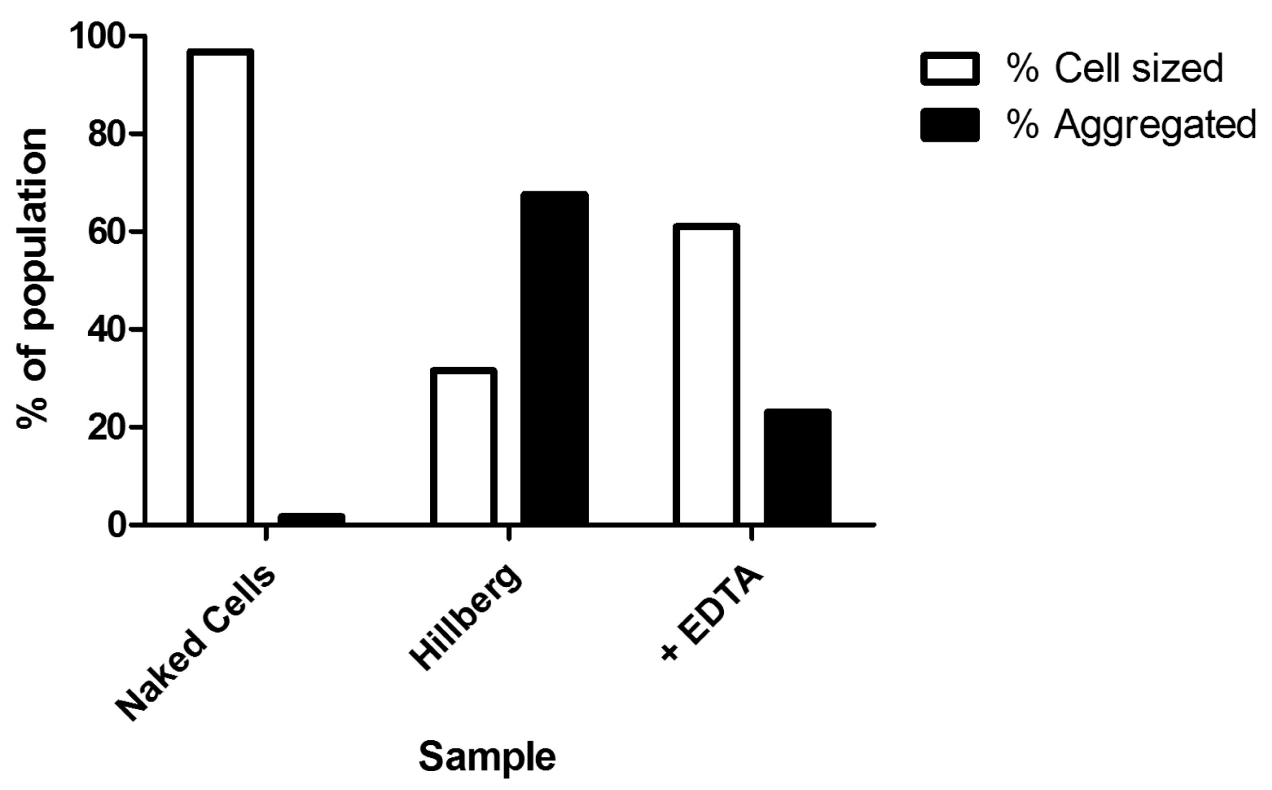

(b)

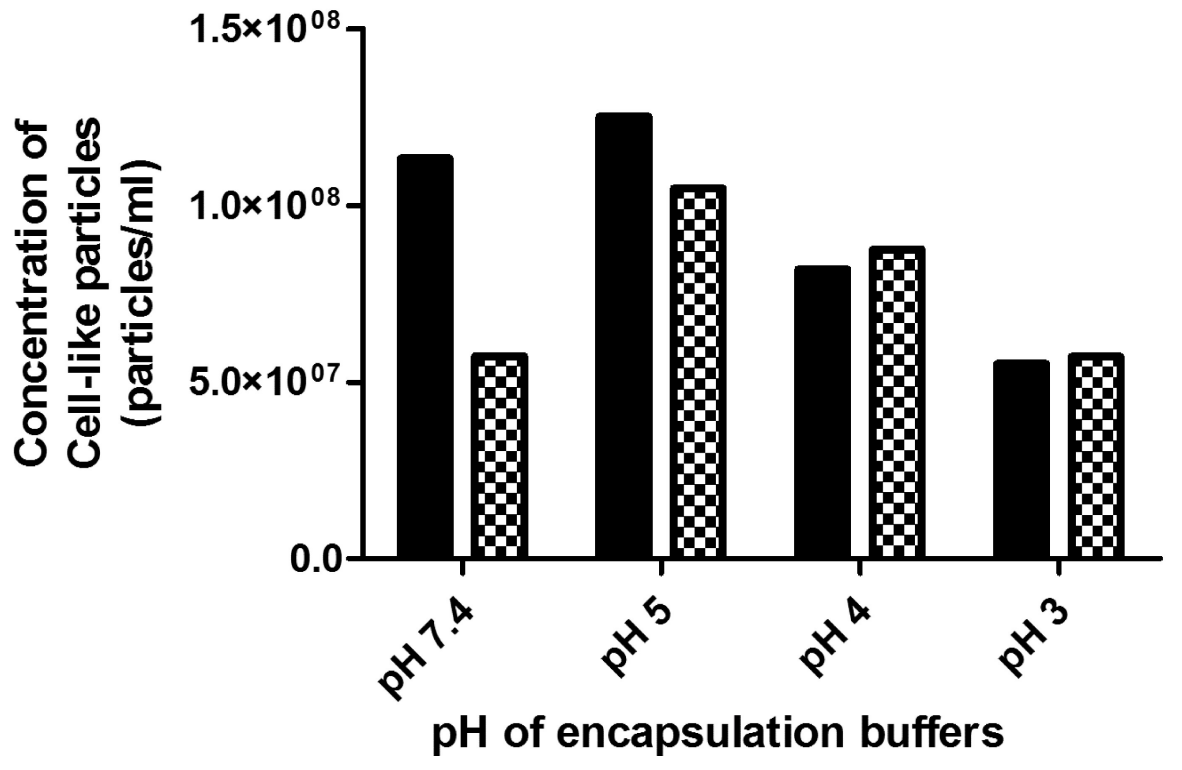

Initial

24h detergent

39 
(a)

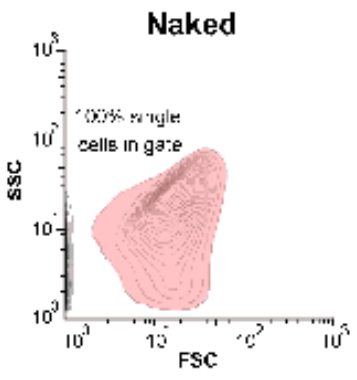

(d)

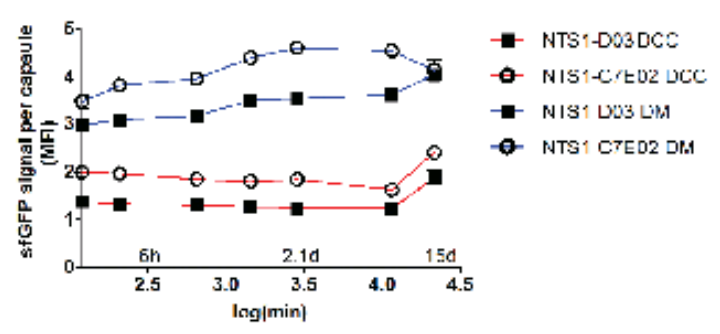

(c)
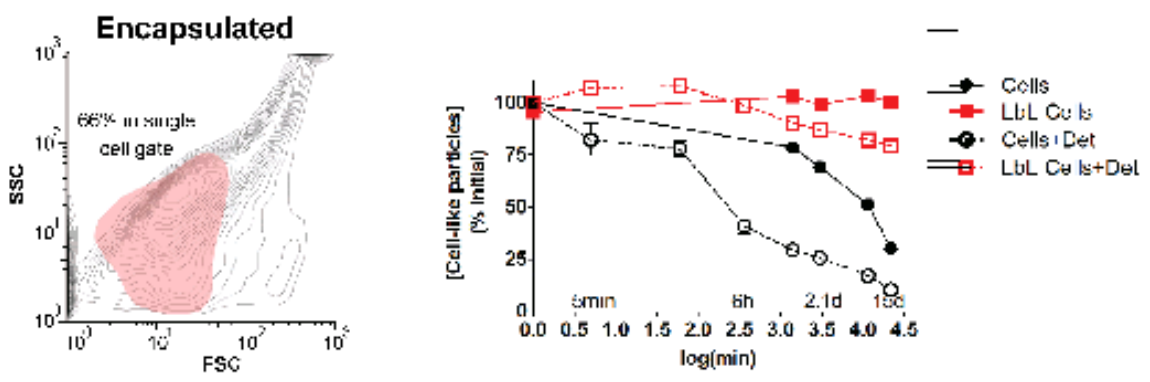

(e)

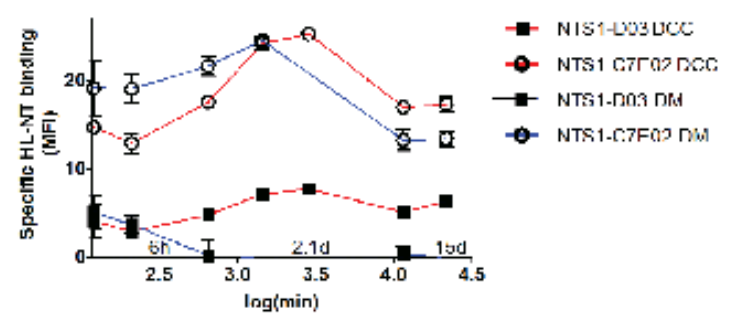


(a)

(b)

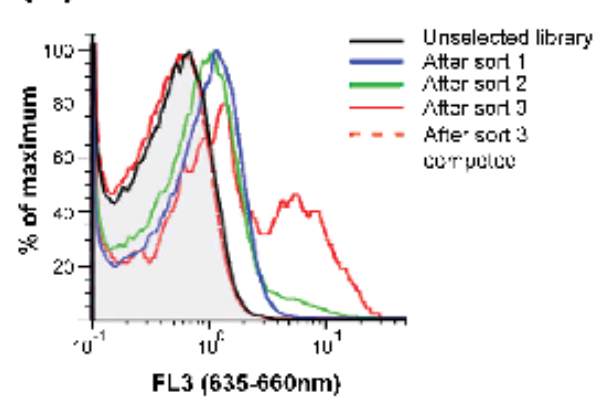

(c)

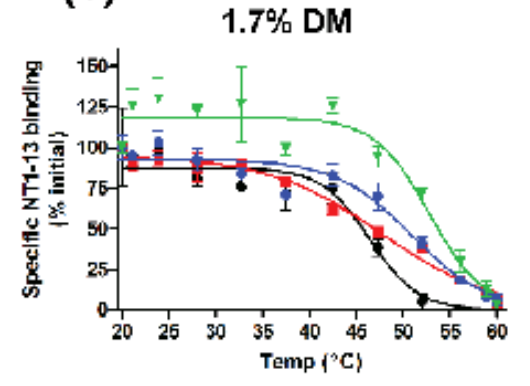

(e)
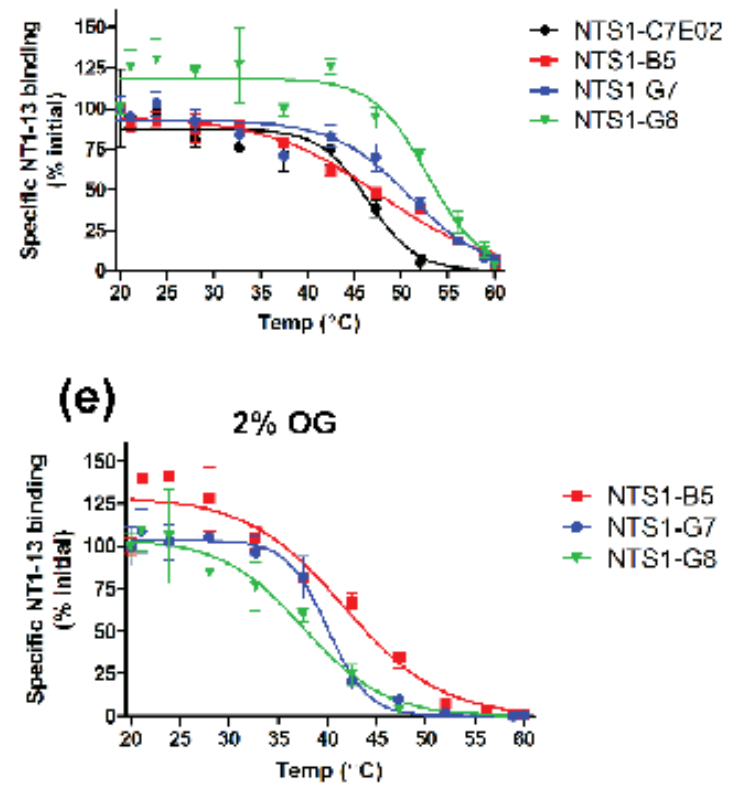

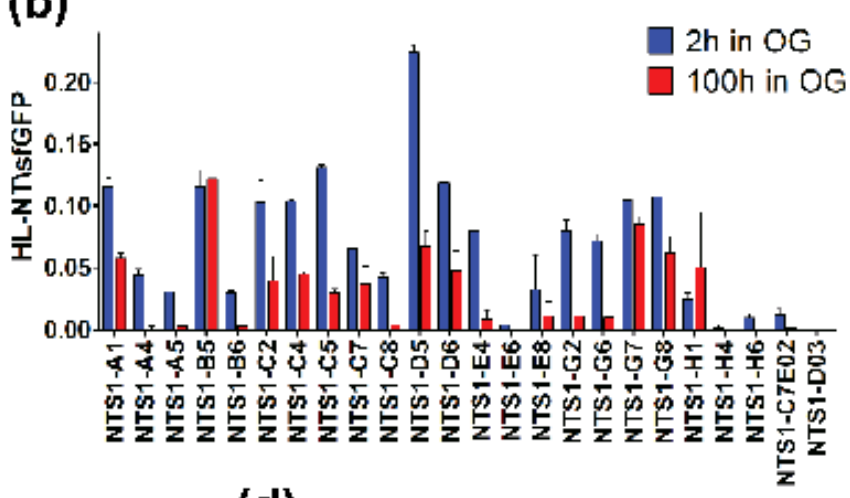

(d)

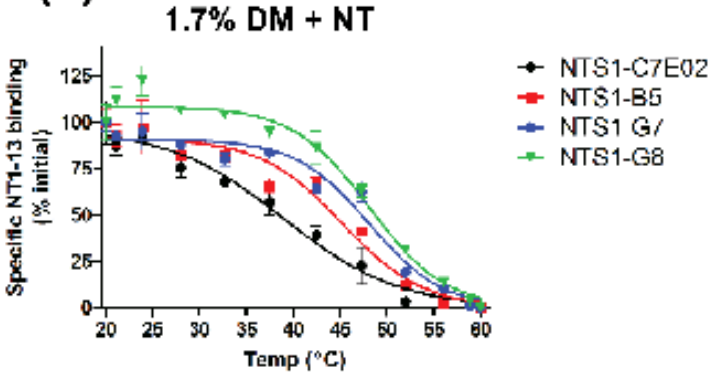

(f) $2 \%$ OG + NT

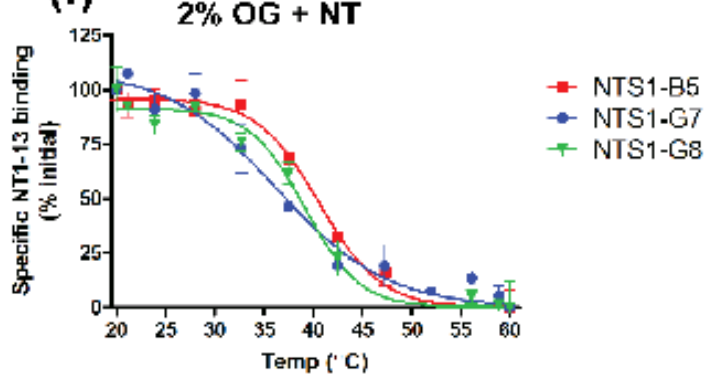


(a)

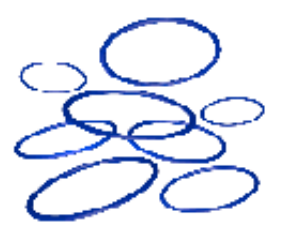

CHESS selected

plasmids
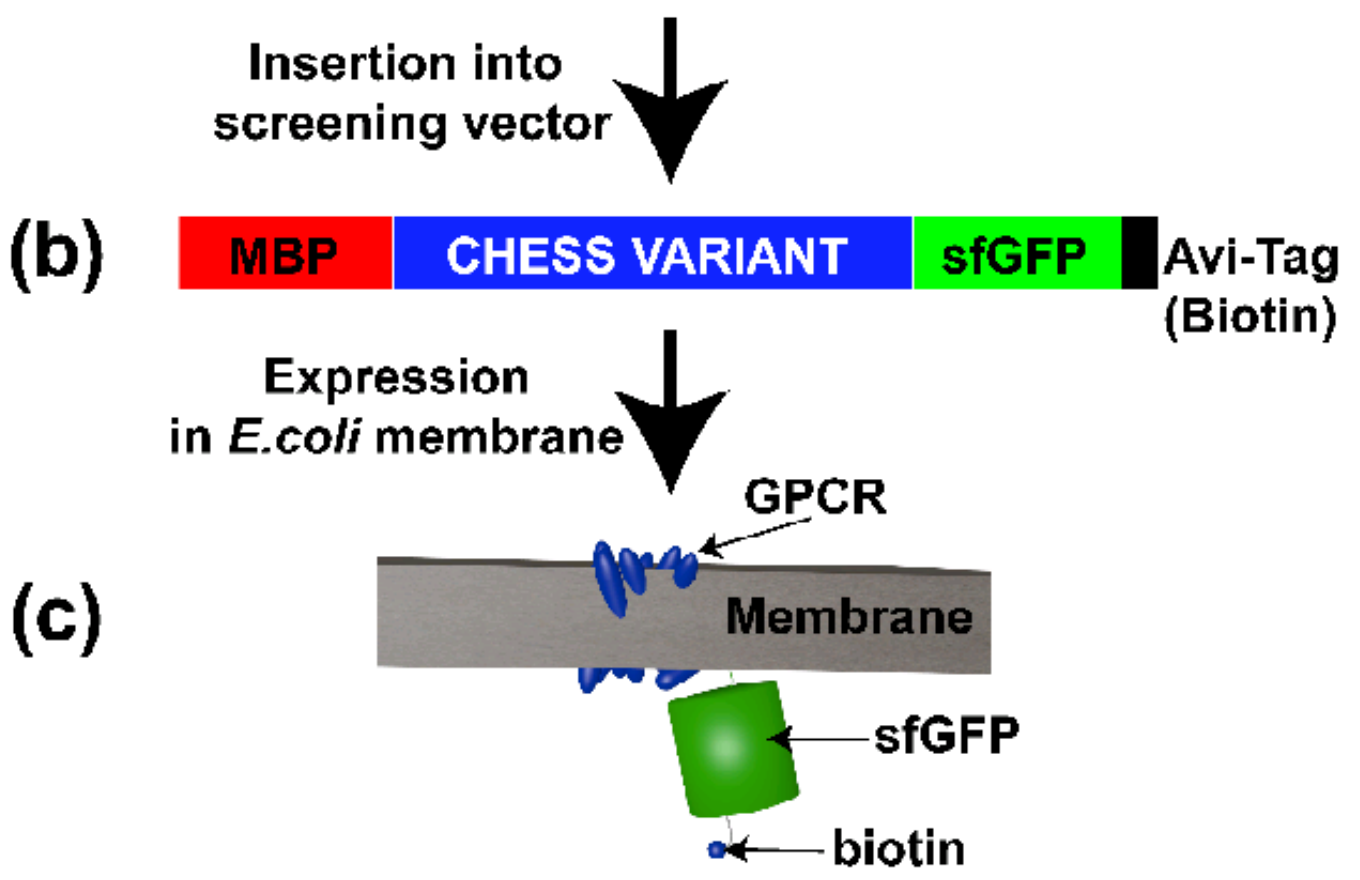

(d) $\begin{gathered}\text { Solubilization in } \\ \text { detergent and } \\ \text { binding to beads }\end{gathered}$

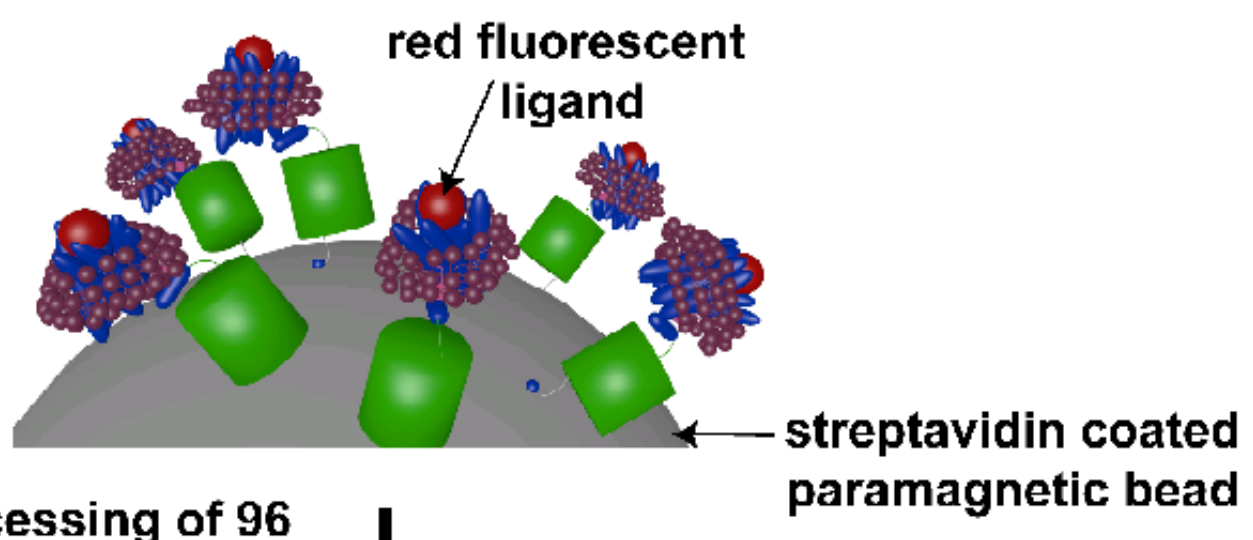

(e) $\begin{gathered}\text { Processing of } 96 \\ \text { samples in parallel } \\ \text { with robotic } \\ \text { magnetic particle } \\ \text { processor }\end{gathered}$

- measure sfGFP fluorescence of beads as measure of protein loading

- Red ligand fluorescence as measure of protein 
(a)

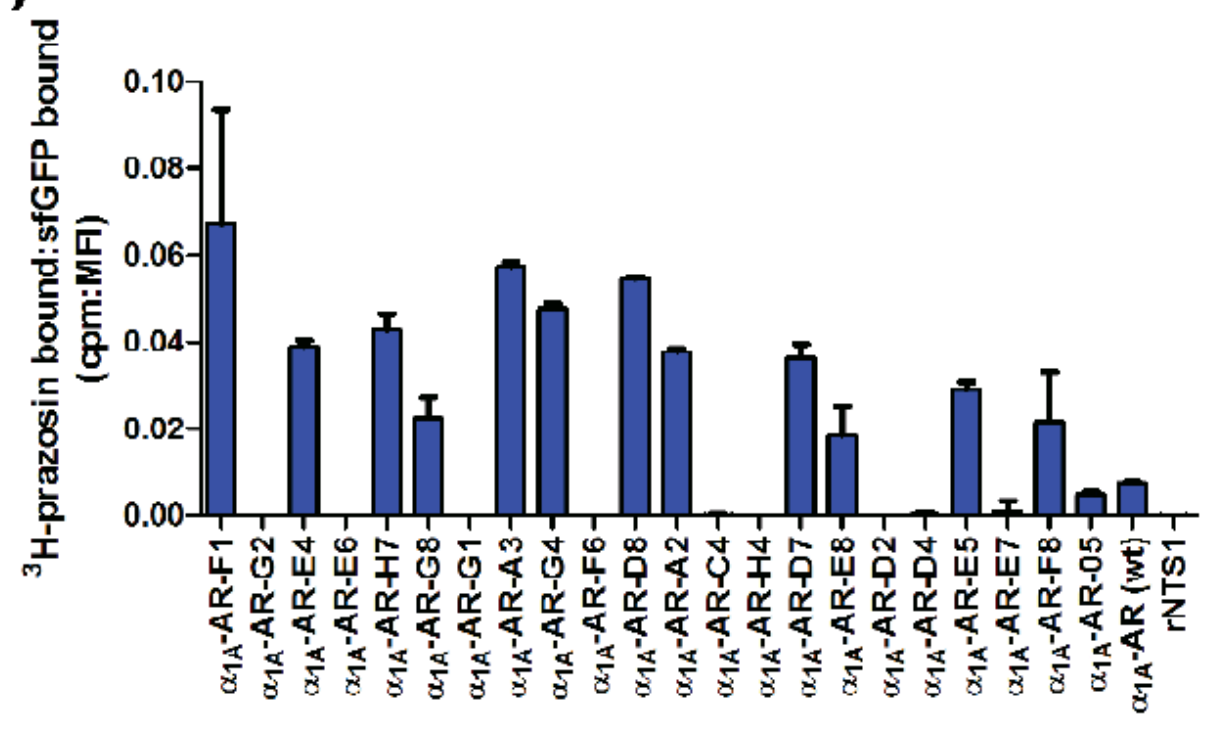

(b)

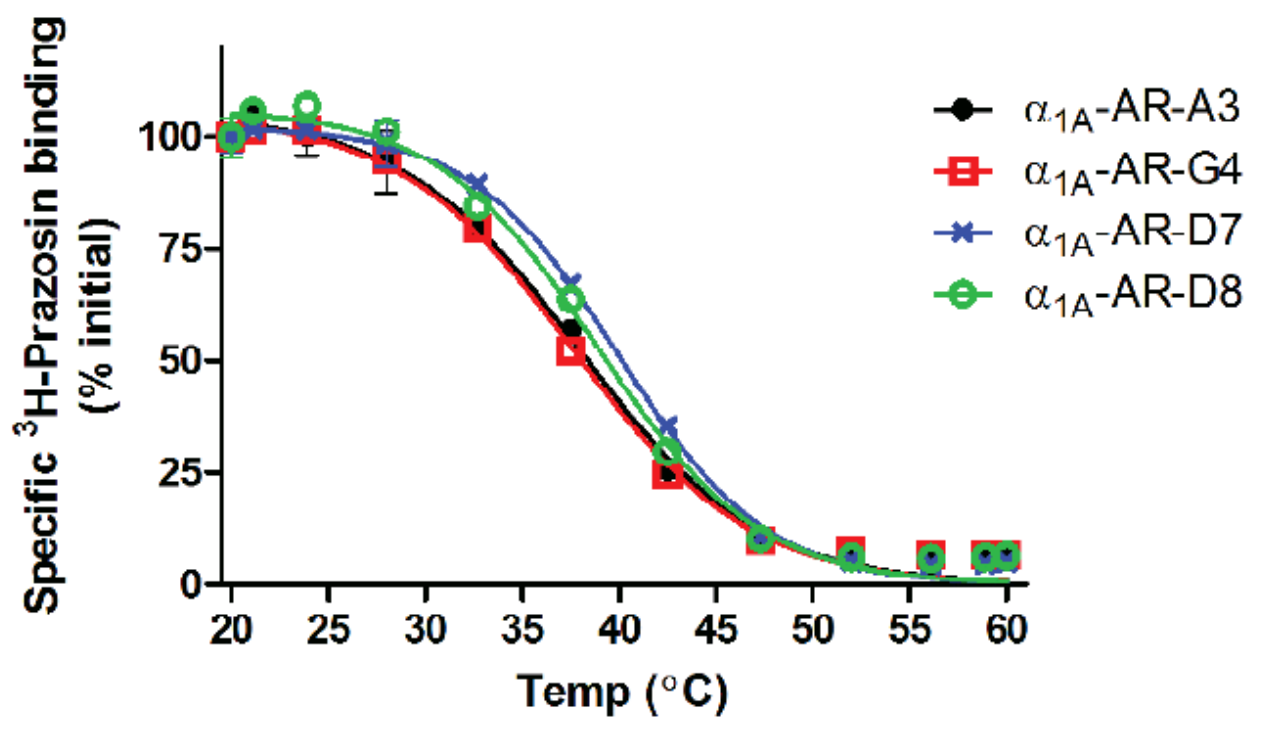

(c)

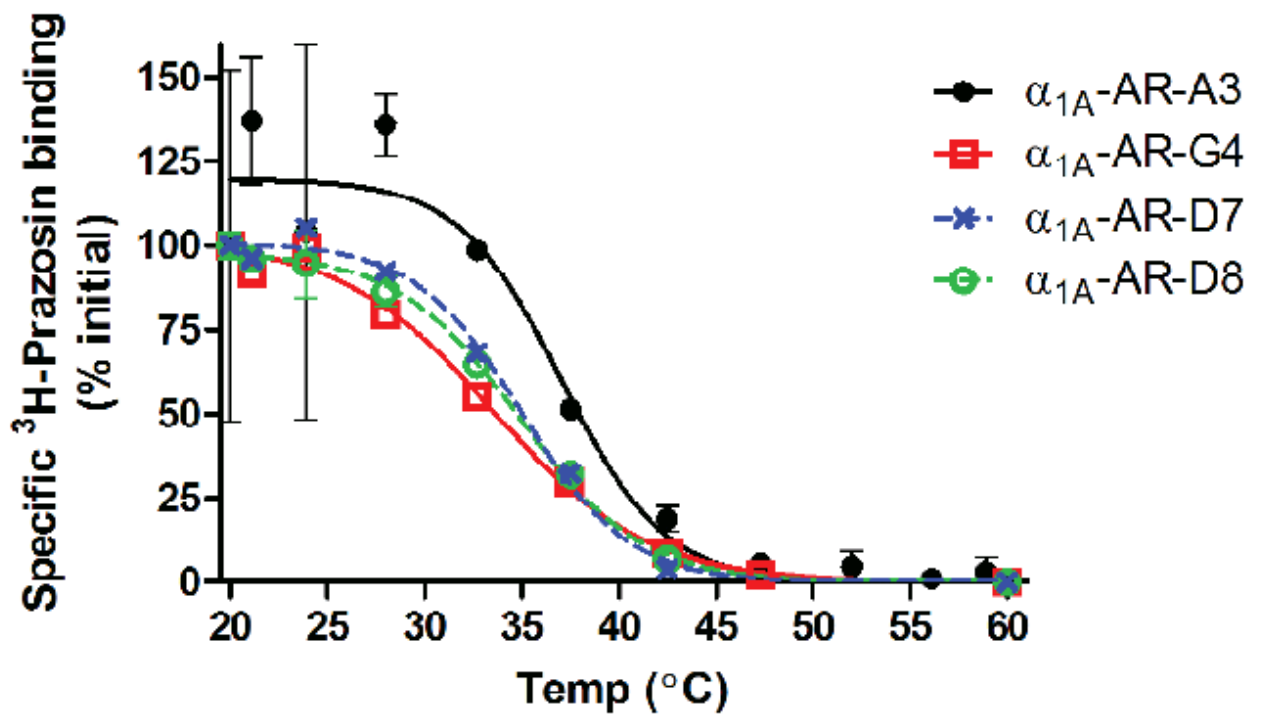


(a)

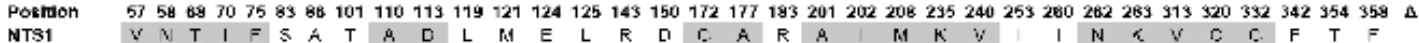
NTS1-D03 V T I F NTE1-C7E02 3 L L L T A D L

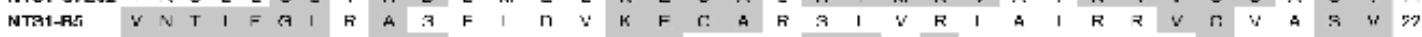

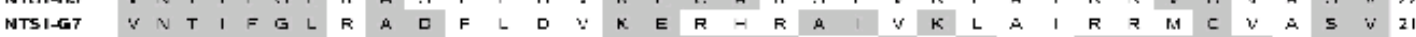

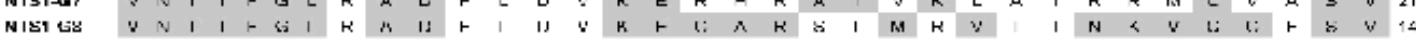
(i+*)

$\mathrm{H}^{2}$ $X \mathrm{HI}$

DrA

(b) Position $1419677176069390103127143149252 \quad 255309312310329353905419421422426430450452456 \quad \Delta$ a

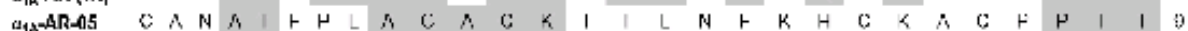

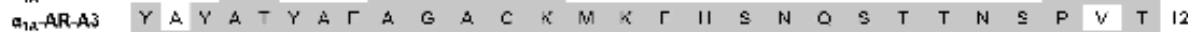

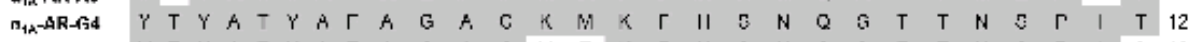

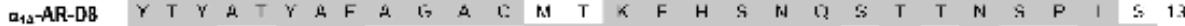
ADAR-DT $Y$ T $Y$ Y

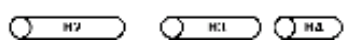




\section{Library of}

Polymeric Containers

Encasing Different

GPCR mutants and their plasmids
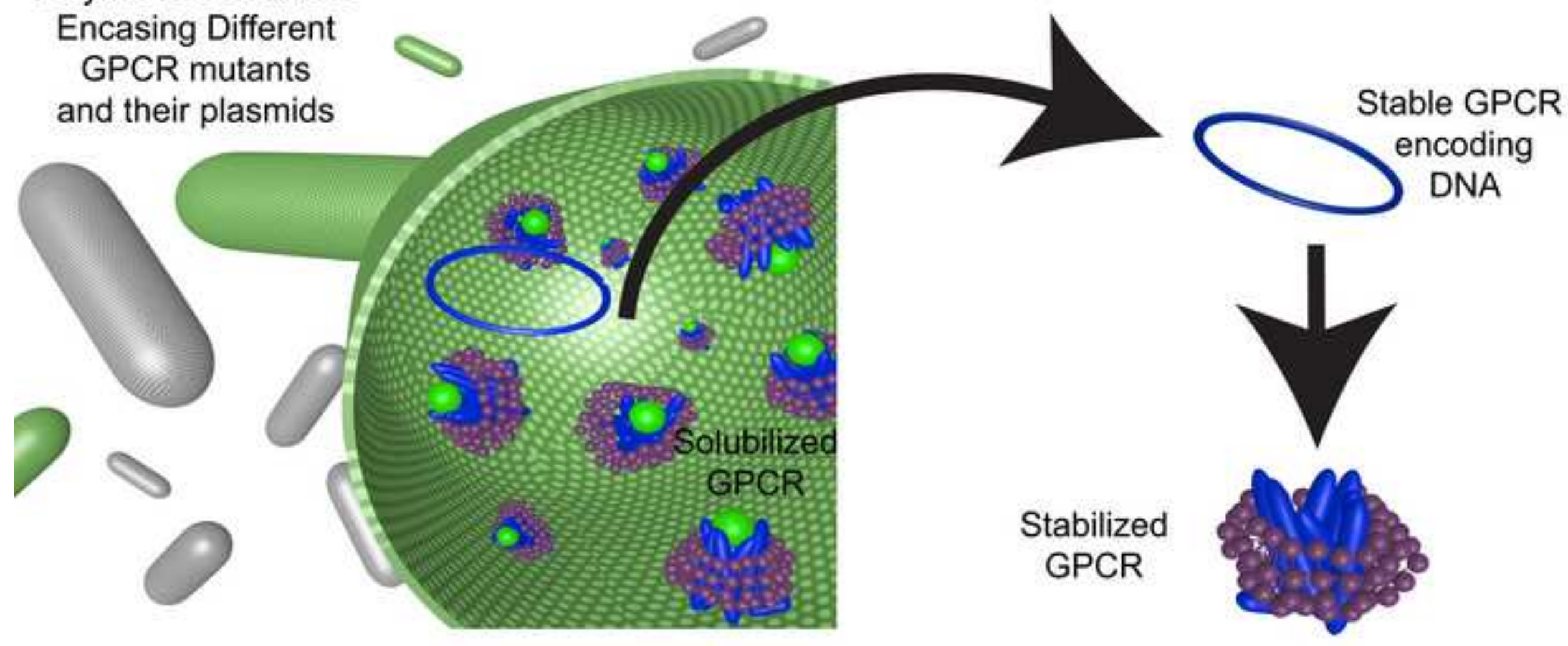

Stabilized GPCR

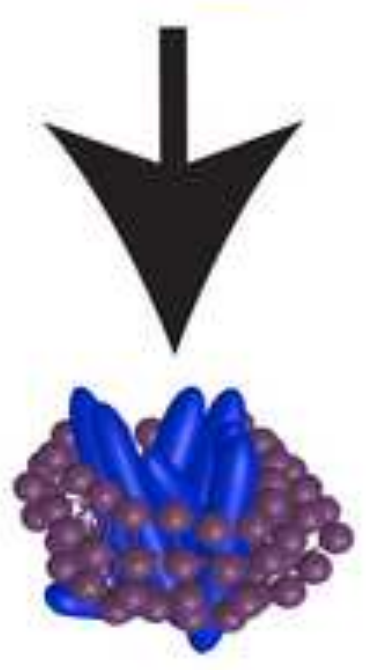


Scott et al Highlights

- GPCRs are unstable when solubilized in short chain detergents for crystallization

- Conversion of GPCR expressing cells into detergent resistant, polymeric containers

- GPCRs and DNA are retained inside the container upon detergent solubilization

- Diverse libraries of containers were screened directly for detergent-stable GPCRs

- Evolved variants are suitable for structural and biochemical analysis 


\section{University Library}

\section{- M M N E R VA A gateway to Melbourne's research publications}

Minerva Access is the Institutional Repository of The University of Melbourne

Author/s:

Scott, DJ;Plueckthun, A

Title:

Direct Molecular Evolution of Detergent-Stable G Protein-Coupled Receptors Using Polymer Encapsulated Cells

Date:

2013-02-08

Citation:

Scott, D. J. \& Plueckthun, A. (2013). Direct Molecular Evolution of Detergent-Stable G Protein-Coupled Receptors Using Polymer Encapsulated Cells. JOURNAL OF MOLECULAR BIOLOGY, 425 (3), pp.662-677. https://doi.org/10.1016/j.jmb.2012.11.015.

Publication Status:

Accepted manuscript

Persistent Link:

http://hdl.handle.net/11343/41838 